\title{
Sentiment-prone investors and volatility dynamics between spot and futures markets
}

\author{
Pilar Corredor, Elena Ferrer and Rafael Santamaria \\ Public University of Navarre
}

\begin{abstract}
This paper analyses the role of investor sentiment in the contemporaneous dynamics of spot and futures markets and in volatility spillovers between them. To explore this issue, we analyse spot and futures markets on stock market indexes in different countries: the S\&P500 for the US, and a representative set of European indexes (CAC40, DAX30, FTSE100, IBEX35 and Eurostoxx50). Consistent with expectations, we have shown that the correlation is not stable with the level of investor sentiment. More specifically, the correlation between the two markets diminishes significantly during periods of high investor sentiment. Moreover, volatility shocks in either market are also found to have less impact during these periods. These results are compatible with behavioural finance theories suggesting that high investor sentiment leads to an increase in noise trading and a decline in arbitrage activity due to institutional investors' attempts to limit their risk exposure.
\end{abstract}

Keywords: Investor Sentiment, noise traders, spot-futures correlation, volatility spillovers

JEL: G10, G13, G14

Corresponding author: Pilar Corredor. Departamento de Gestión de Empresas. Universidad Pública de Navarra. Campus de Arrosadia s/n. 31.006 Pamplona (SPAIN). Ph. 34948 169380. Fax 34948169404. E-mail: corredorp@unavarra.es

(C) 2014. This manuscript version is made available under the CC-BY-NC-ND 4.0 license http://creativecommons.org/licenses/by-nc-nd/4.0/ 


\section{Sentiment-prone investors and volatility dynamics between spot and futures markets}

\section{1. -Introduction}

The introduction of futures markets brought about a significant improvement in the news transmission mechanism by allowing more rapid adjustment of prices to new information (Antoniou et al, 1998) and may have expanded cross-market information flows by attracting new traders (Cox, 1976). This may well determine the way information is incorporated into both spot and futures prices. The extent of the impact will depend upon the types of traders active in the two markets (Antoniou et al, 1998).

Circumstances affecting the investor mix in the spot or the futures market, liquiditydriven changes in the transaction costs on asset trading, or both of these in conjunction could alter information flow dynamics between spot and futures markets ${ }^{1}$. A potentially key variable in this issue is investor sentiment. Noise traders tend to be more active in bullish than in bearish markets (Baker and Stein, 2004) and to have less capacity to react to news, since their overconfidence and self-attribution biases, which increase in the presence of high market sentiment. Yu and Yuan (2011) also argue that sentimentdriven investors participate and trade more aggressively in high-sentiment periods, due to their reluctance to take short positions in low-sentiment periods. Behavioural finance has shown that, when investor sentiment is high, arbitrage activity by informed traders slows due to noise trading risk, that is, risk arising from the unpredictability of noise traders' behaviour. In periods such as these, informed investors will stay out of the market (Shleifer and Vishny, 2003). Sophisticated traders, aware of the overpricing that accompanies moments of high market sentiment, may also significantly reduce their exposure at such times, thereby allowing the influence of noise trader behaviour in price setting to increase. This difference in trading behaviour can affect trading volume, investor mix and effective transaction costs in both these markets.

This framework raises the interest in examining the impact of the level of investor sentiment on the contemporaneous dynamics of the spot and futures markets, and on volatility spillovers between both markets. This, as far as we know, is the first attempt to explore this issue. The focus of the study is to analyse the joint dynamics of several stock indexes and their respective futures contracts, specifically, the S\&P500 index for

1The literature has in fact shown that regulatory reform or changes in the overall economic environment have had considerable impact on these dynamics. See, for example, the effect of variation in the transaction costs of futures markets (Aragó et al, 2003) or the changing nature of volatility contagion between financial markets (Saha and Chakrabati, 2011). 
the US market, and the CAC40, the DAX30, the IBEX35, the FTSE100, and the Eurostoxx50 for the European market.

This study makes several contributions to the literature. Firstly, it focuses on the effect of investor sentiment on trading volume in the spot and futures markets. During periods of high market sentiment, while noise traders become more active, informed traders try to reduce their exposure, so the net effect becomes an empirical issue. This analysis enables us to test the "create space" effect (De Long et al, 1990), which is described in more detail in the theoretical framework section.

Secondly, in connection with the above, this paper focuses on whether the efficiency of response and information flow between spot and futures markets is altered when a period of high market sentiment results in a massive influx of noise traders upsetting the existing investor mix in both markets. If such an alteration occurs, correlation between the two markets will be affected and informational efficiency reduced as a consequence. This issue will be explored using bivariate GJR (Glosten-JagannathanRunkle, 1993) models to examine the time-varying correlation between financial markets in the light of investor sentiment.

Informational efficiency can also be affected by the amount of information flow between markets. The third contribution of this paper is to investigate the issue along these lines. The extent of the potential effect of investor sentiment on spillovers between the two markets is observed by analysing the impact of own-market or other-market news on volatility and the extent of the asymmetric volatility effect brought about by good or bad news from either market. Behavioural finance theory indicates that in periods of high market sentiment order flows are less informative, because the strong presence of noise traders impedes a rational market response to the news. Thus, in line with the "noise trading" hypothesis, we can expect information shocks to have less impact and information efficiency to diminish.

Finally, the paper presents some of the practical implications stemming from the findings. As well as for academics, this study holds interest for practitioners, because knowledge and understanding of the variables influencing the degree of integration between the two markets and the mechanisms by which news is incorporated into spot and futures prices and transmitted across markets are important when considering trading or hedge positions. Thus, the discussion section briefly describes two applications which demonstrate the effects deriving from changes in correlation and information flow between spot and futures markets due to changes in investor sentiment. In the first application we analyse the effectiveness of dynamic hedging when correlation between 
the two markets is estimated with, versus without, investor sentiment. In the second, we test whether the level of investor sentiment has a significant impact on the level of mispricing in futures contracts.

The rest of this article comprises five more sections. Section 2 discusses the theoretical framework for the analysis and the formulation of the hypotheses to be tested. Section 3 describes the data. Section 4 presents the empirical model and the results. Section 5 discusses two applications of the results obtained in the previous section and section 6 summarises the main conclusions.

\section{Theoretical Framework and Testable Hypotheses}

The behavioural finance literature suggests that investor sentiment, defined as investors' opinions regarding future cash flows and investment risk (Chang et al, 2012), affects trading decisions. The influence of investors' future expectations may result in mispricing that will affect pricing models. Recognition of noise traders and their responses to investor sentiment completes the classic asset pricing theory. Indeed, Yang and Li (2013) or Yang and Cai (2014) among others have recently incorporated investor sentiment into the asset pricing model, by adjusting the economic valuation model to the reality of the asset market.

De Long et al (1990) present a simple overlapping-generations model of an asset market in which irrational noise traders with erroneous stochastic beliefs affect prices and earn higher expected returns. The model presents two possible effects: the transitory effect and the permanent effect. The former captures the influence of noise trading on excess returns due to contemporaneous changes in sentiment ("price-pressure" and "hold-more" effects). The latter is related to variations in market sentiment due to noise trading (the "Friedman" and "create- space" effects) and their impact on return volatility. The net effect will depend on the relative weight of the individual effects (Lee et al, 2002).

The main effect in the model, and the one of most interest for our study, is the "create space" effect, which is based on the notion that, in order to benefit from noise traders' misperceptions, sophisticated investors must bear this greater risk. Being risk averse, sophisticated investors reduce their exposure as market risk increases with a stronger presence of noise traders. Thus, the optimism or pessimism of noise traders produces transitory deviations from fundamentals and price fluctuation. A drop in trading by sophisticated investors may also have an important impact on effective transaction costs by provoking an increase in market impact trading costs. All these responses will have 
obvious implications deriving from a reduction in the informational efficiency of the market

The degree of correlation basically depends on informational efficiency. If markets are informationally efficient, spot and futures returns should be perfectly correlated Informational efficiency cannot be assumed to be stable over time, irrespective of the investor mix or the width of the no-arbitrage band. The "create space" effect will therefore be relevant in a context of high market sentiment and in stocks favoured by noise traders. Rational investors prefer less exposure in the equity market, because they know that some kind of assets are over-priced and will tend to revert in the mid to long term (see Baker and Wurgler, 2006 or Chan, 2014 among others).

Furthermore, the "create space" effect will not affect spot and futures markets to the same degree. Futures markets are dominated by institutional investors (Kavussanos et al 2008 and Bohl et al, 2011), who are assumed to be informed or rational. These informed or sophisticated traders, will reduce their arbitrage activity and their exposure in equity markets, and will thereby reduce trading volume to a greater extent in futures markets than in spot markets ${ }^{2}$. Change in the investor mix, however, will be more marked in the spot market, which will see a more significant increase in the presence of noise traders, while the futures market will continue to be dominated by institutional investors.

In summary, during periods of market optimism, the "create space" effect will dominate other effects, so the no-arbitrage band will widen and, within that band, the price correlation of these two markets will weaken. This leads us to our first hypothesis.

H1: High market sentiment reduces correlation between spot and futures markets.

In a perfect market, the relationship between price movements in the futures index and underlying spot markets should be instantaneous, because they are both driven by the same market information. Under certain conditions (leverage, liquidity, transaction costs, investor mix), however, one market may assimilate new information more quickly than the other, thereby affecting volatility spillovers.

Yang and $\mathrm{Li}$ (2013) extend the noisy rational expectation model (Grossman and Stiglitz, 1980) to present an analytical solution for the equilibrium price in the presence of sentiment, based on its decomposition into a rational term and a sentiment term. The quality of information improves with the increasing presence of rational investors. This curbs the spread of sentiment, strengthens the role of information shocks and increases

\footnotetext{
${ }^{2}$ Note that the extent of the effect on trading volume in the spot market is unclear, because the reduced activity of institutional investors may be offset, wholly or in part, by a significant influx of noise traders.
} 
market efficiency. Thus, in periods of high investor sentiment, the opposite effect will take place due to the "create space" effect, which, as already noted, reduces the proportion of rational investors in the market.

Furthermore, according to the noise trading hypothesis, order flow is less informative when investors are optimistic. Shleifer and Summers (1990) or Peri et al (2014) state that, when arbitrage is limited and investor demand for securities responds to noise, security prices move in response to these changes in demand as well as to changes in fundamentals. In these circumstances, prices move more than their fundamentals would suggest, in simultaneous response to changes in the level of investor sentiment and to news ${ }^{3}$.

During periods of high investor sentiment, these biases will make investors in general, and noise traders in particular, less alert to information coming from their own market, thus reducing the impact of news on volatility. By the same token, they will also pay less attention to information coming from the other market. Furthermore, noise traders' reaction to bad news that contradicts their prior beliefs will have less impact on price formation. This means that, during periods of high investor sentiment, the impact of news from either market will be less asymmetric. This leads us to our second and third hypotheses, which state as follows:

H2: During periods of high market sentiment, the impact of own-market news on volatility will be weaker and less asymmetric.

H3: During periods of high market sentiment, the impact of other-market news on volatility will be weaker and less asymmetric.

\section{Database}

For the implementation of the analysis, this study uses daily closing prices and trading volume of the spot and futures markets for a period running from February 2001 to December 2011. The data are taken from the US stock market and four European markets: namely France, Germany, the United Kingdom and Spain. The EuroStoxx50 is also included in order to represent the Euro zone. The reason for this choice of European markets is that the economies of the UK, France and Germany are considered, along with the US and Japan ${ }^{4}$, as extremely prominent on the global stage (Chang et al, 2012). According to the World Federation of Exchanges classification for 2011, the London SE

\footnotetext{
${ }^{3}$ Daniel et al (1998) assume that investors are overconfident about their private information. If investors are also affected by self-attribution bias, they will react asymmetrically to confirming versus disconfirming pieces of news and become even more over confident after receiving confirming news. Self-attribution bias leads investors to under react to the release of public information. The conservatism bias hypothesis states that investors do not fully adjust their priors to the arrival of new information (Barberis et al, 1998).

${ }^{4}$ Although it would have been interesting to include Japan, the necessary data were unavailable.
} 
Group is the largest European stock exchange grouping in terms of capitalization, followed by NYSE Euronext (Europe), the Deutsche Börse and the BME Spanish Exchanges. The homogeneity of their financial development levels does not rule out some variation in shareholder structure, corporate governance (see La Porta et al, 1998) and cultural dimensions (see Hofstede, 2001) between the selected European countries, however. The market sample also includes representatives of both the Anglo Saxon and Continental financial systems. This combination of similarity and diversity strengthens the relevance of our findings by allowing us to determine whether institutional factors, unrelated to financial development, play a significant role in the impact of investor sentiment on cross-market correlation and volatility spillovers.

The closing prices data, taken from the Datastream database (Thomson Financial), refer to the S\&P500 index for the US stock market and to the five key European stock market indexes, namely, the CAC40 for France, the DAX30 for Germany, the FTSE-100 for the UK, the IBEX35 for Spain, and the EuroStoxx50 index. The closing prices of the respective futures contracts were drawn from the Bloomberg database. The returns for the spot index $\left(S_{t, i}\right)$ and the futures index $\left(F_{t, i}\right)$ computed each day $t$ for each index $i$ are defined as $R_{s, t, i}=100 \cdot \ln \frac{S_{t, i}}{S_{t-1, i}}$ and $R_{f, t, i}=100 \cdot \ln \frac{F_{t, i}}{F_{t-1, i}}$

The trading volume data on these markets (spot and futures) are drawn from the Datastream and the Bloomberg database, respectively. The variable used in the analysis is abnormal trading volume ${ }^{5}$, calculated for each index as:

$$
A V_{t}^{i, m}=\log V_{t}^{i, m}-\sum_{k=1}^{200} \log V_{t-k}^{i, m} / 200
$$

where $V_{t}^{i, m}$ is the ordinary trading volume of each index $i$ (S\&P500, CAC40, DAX30, IBEX35, FTSE100 and EuroStoxx50) on day $t$, for each market $m$ ( $\mathrm{s}=$ spot and $\mathrm{f}=$ futures).

Another of the variables considered in this analysis is investor sentiment. Previous studies have used a variety of sentiment indicators, and there is no consensus as to the best means of representing this unobservable variable ${ }^{6}$. In this paper we use the survey data of the American Association of Individual Investor (AAII) for the US market and a homologous survey of the European market: SentixEuroStoxx 50, in line with DeBondt (1993), Lee et al (2002) or Brown and Cliff (2004) among others.

The American Association of Individual Investors (AAII) survey began, in 1987, as a weekly survey of randomly selected AAII members. It asks participants to predict the

\footnotetext{
${ }_{5}^{5}$ The selected measure is similar to that used in papers such as Llorente et al (2002) or Covrig and Ng (2004). Given that our interest is in trading volume in futures markets, we use trading volume instead of turnover.

${ }^{6}$ See Brown and Cliff (2004) and Baker and Wurgler (2006) for indicators used in previous research.
} 
likely direction of the stock market during the next six months and measures the percentages of individual investors responding "up", "down", and "the same". The participants are randomly chosen from approximately 100,000 AAII members. Each week, the AAII compiles the results based on survey answers and labels the market as bullish, bearish or neutral. These results are published as 'investor sentiment' in monthly editions of AAII Journal.

For a measure of investor sentiment in the European indexes analysed, we use survey data from SentixEuroStoxx 507. Since this survey began in February 2001, it has surveyed Sentix investors weekly, and currently has over 3100 registered participants, more than $77 \%$ of whom are individual investors. Participants are asked whether they are bullish, bearish, neutral, or have no opinion with regard to the future trend of the EuroStoxx50 stock index over the following one- and six-month periods ${ }^{8}$.

We use the two survey measures (Sentix and AAII) as the spread between the percentages of bullish and bearish investors. According to the level of investor sentiment, each week is recorded as either a bullish (above-the-median) sentiment week or a bearish (below-the-median) sentiment week ${ }^{9}$. Both the AAII and the Sentix survey meet the necessary criteria with respect to frequency and trader awareness and both capture market sentiment well because they are calculated from a direct survey of the expected future state of the market. The results of the two surveys are also comparable because of the similarity of the question they put to the participants. Investor sentiment data were also drawn from Datastream.

We use a direct survey measure of investor sentiment (explicit measure) instead of relying on other market-based (implicit) measures, since the complementary techniques needed to construct them could bias the final results. For the purposes of our analysis, moreover, we require a short-term measure of sentiment. The one we have selected is frequently-published and updated and its mode and date of construction are known and understood by traders. In fact, these surveys are a common measure of sentiment in the popular press and frequently mentioned in financial press articles ${ }^{10}$. Furthermore, since this is a public survey, it is available to all market agents, in contrast to the indirect measures mentioned earlier, which are calculated from whatever variables deemed appropriate, the choice potentially having more than negligible effects (see Corredor et

\footnotetext{
${ }^{7}$ In the absence of any sentiment measure of this kind for the UK, we consider this a valid approximation.

8 The results shown are those obtained using the Sentix 6 month-ESX 50 Index for consistency with the AAII. For robustness checks, we later repeat the analysis using the Sentix 1 month-ESX 50 Index.

${ }_{9}$ Replies to the weekly survey are accepted up to Friday of the week in question, but the results are not published until the following Monday before trading opens. For the purposes of our study, we take the moment of optimism/pessimism to be Friday when the survey replies are being given. Repetition of the analysis using a dummy variable beginning the day after close of survey produced similar results. The results are available upon request.

10 For example, Barron's and the Financial Times.
} 
al, 2013). Both our selected measures possess the above-mentioned characteristics, and therefore suit the purposes of our analysis.

Finally, due to the nature of the target respondent, this survey is primarily a measure of individual investor sentiment. Given that the aim of this paper is to explore the relationship between spot and futures markets in high sentiment periods using arguments based largely on the observation of noise trader behaviour, the key variable to be incorporated is the level of optimism in individual investors, which, as already noted, is measured by the above mentioned surveys. This makes them more suitable for our present purposes than other measures proposed in the literature, in which individual investor sentiment is not measured directly but through approximation based on implicit market trading measures.

\section{Methodology and Results}

\subsection{Methodology}

To model the effects of investor sentiment on correlation between spot and futures index returns and between the linkage in the second moments of the two markets, we use a bivariate GJR process.

The model (henceforth, Model 1) for each index $i$ ( $i=$ S\&P500, CAC40, DAX30, IBEX35, FTSE100 and EuroStoxx50) takes the following form ${ }^{11}$ :

$$
\begin{aligned}
& R_{s, t, i}=A_{0, i}+A_{1, i} R_{s, t-1, i}+A_{2, i}\left(S_{t-1, i}-A_{3, i} F_{t-1, i}\right)+e_{s, t, i} \\
& R_{f, t, i}=B_{0, i}+B_{1, i} R_{f, t-1, i}+B_{2, i}\left(S_{t-1, i}-A_{3, i} F_{t-1, i}\right)+e_{f, t, i} \\
& \sigma_{s, t, i}^{2}=\alpha_{0, i}+\alpha_{1, i} e_{s, t-1, i}^{2}+\alpha_{2, i} \sigma_{s, t-1, i}^{2}+\alpha_{3, i} D_{s, t-1, i} e_{s, t-1, i}^{2}+\alpha_{4, i} \varepsilon_{f, t-1, i}^{2}+\alpha_{5, i} D_{f, t-1, i}^{0} \varepsilon_{f, t-1, i}^{2} \\
& \sigma_{f, t, i}^{2}=\beta_{0, i}+\beta_{1, i} e_{f, t-1, i}^{2}+\beta_{2, i} \sigma_{f, t-1, i}^{2}+\beta_{3, i} D_{f, t-1, i} e_{f, t-1, i}^{2}+\beta_{4, i} \varepsilon_{s, t-1, i}^{2}+\beta_{5, i} D_{s, t-1, i}^{0} \varepsilon_{s, t-1, i}^{2} \\
& \sigma_{s f, t, i}=\left(\gamma_{0, i}+\gamma_{1, i} S E N T_{t}\right) \sigma_{s, t, i} \sigma_{f, t, i} ; \quad \mathrm{i}=1,6 ;
\end{aligned}
$$

where $\left(S_{t-1, i}-A_{3, i} F_{t-1, i}\right)$ is the error correction term imposing the long-term equilibrium on index $i$ in the two markets; $e_{s, t, i}\left(e_{f, t, i}\right)$ is the innovation in the spot (futures) market at day $t$ for index $i ; \sigma_{s, t, i}^{2}=\operatorname{var}\left(e_{s, t, i} / \Omega_{\mathrm{t}-1, \mathrm{i}}\right)$ is the conditional variance of the spot market and $\sigma_{f, t, i}^{2}=\operatorname{var}\left(e_{f, t, i} / \Omega_{\mathrm{t}-1, \mathrm{i}}\right)$ is the conditional variance of the futures market, where $\Omega_{\mathrm{t}, \mathrm{i}}$ is the information set available at $\mathrm{t}$ for index $i$.

As shown, in the above variance equation the cross-market innovations have been added to a GJR specification. It is interesting to note that the innovation $\varepsilon_{s, t, i}\left(\varepsilon_{f, t, i}\right)$ is used instead of $e_{s, t, i}\left(e_{f, t, i}\right)$. The reason for this choice is the intense cross-correlation

\footnotetext{
11 Although not reported in the tables, some diagnostic tests of the residuals were performed. No indications of model misspecification were observed. The autocorrelations and partial correlations for the squared standardized residuals for stock index and index futures returns are all insignificantly different from zero.
} 
between $e_{s, t, i}$ and $e_{f, t, i}$ which could lead to misleading estimates. The innovation $\varepsilon_{s, t, i}$ $\left(\varepsilon_{f, t, i}\right)$ is the information from the spot (futures) market which is transmitted to the futures (spot) market and is not included in $e_{f, t, i}\left(e_{s, t, i}\right)$. Thus, $\varepsilon_{s, t, i}\left(\varepsilon_{f, t, i}\right)$ is orthogonal to $e_{s, t, i}\left(e_{f, t, i}\right)$. Formally, $\varepsilon_{s, t, i}\left(\varepsilon_{f, t, i}\right)$ is computed as the residuals from a regression which can be written as $e_{s, t, i}\left(e_{f, t, i}\right)=k_{0, i}+k_{1, i} e_{f, t, i}\left(e_{s, t, i}\right)+\varepsilon_{s, t, i}\left(\varepsilon_{f, t, i}\right) . \quad \varepsilon_{s, t, i}$ and $\varepsilon_{f, t, i}$ have been incorporated into the $\sigma_{s, t, i}^{2}$ and $\sigma_{f, t, i}^{2}$ equations respectively, to analyse the volatility spillover between the two markets on each index $i . D_{s, t, i}\left(D_{f, t, i}\right)$ is a dummy variable which is 1 if $e_{s, t, i}<0\left(e_{f, t, i}<0\right)$ y 0 otherwise; $D_{s, t, i}^{0}\left(D_{f, t, i}^{0}\right)$ is a dummy variable which is 1 if $\varepsilon_{s, t, i}<0\left(\varepsilon_{f, t, i}<0\right)$ and 0 otherwise. In the specification of the covariance, the constant correlation implied in the cost-of-carry model is assumed ${ }^{12}$.

In order to test hypothesis 1, we introduce the dummy variable (SENT) into the model to allow this correlation to change as a function of investor sentiment. As already stated, this variable takes a value of 1 when the sentiment index is above the median level and 0 otherwise. As sentiment proxies, we use the AAII for the US index and the Sentix index for the European indexes under analysis. The coefficient $\gamma_{1, i}$ of these indexes indicates whether there is a change in contemporaneous correlation between the futures and spot markets. Consistent parameter estimates are obtained using the Berndt-HallHall-Hausman (BHHH) algorithm.

Furthermore, these equations allow these innovations $\left(\varepsilon_{s, t, i}\right.$ and $\left.\varepsilon_{f, t, i}\right)$ to influence the conditional volatility asymmetrically, as do their own innovations $\left(e_{s, t, i}\right.$ and $\left.e_{f, t, i}\right)$. Thus, $\alpha_{4, i}$ and $\beta_{4, i}$ measure the magnitude effect, whereas $\alpha_{5, i}$ and $\beta_{5, i}$ measure the sign effect. The intuitive interpretation of these coefficients is very similar to that of their own innovations, but they are relative to cross-market volatility spillovers.

In order to analyse the effect of sentiment on informational efficiency, we adjust Model 1 to include the dummy variable (SENT) described earlier, but now also associated to any information coming from the market under analysis (Model 2) and to negative news coming from its own market (Model 3). We also include the SENT variable as it affects information coming from the other market (Model 4) and the asymmetric response of volatility to news coming from the other market (Model 5). The unrestricted model, onto which we impose different restrictions to create the rest of the abovementioned models, is presented below:

12 The covariance specification is similar to that used in Koutmos and Tucker (1996) 


$$
\begin{aligned}
R_{s, t, i} & =A_{0, i}+A_{1, i} R_{s, t-1, i}+A_{2, i}\left(S_{t-1, i}-A_{3, i} F_{t-1, i}\right)+e_{s, t, i} \\
R_{f, t, i} & =B_{0, i}+B_{1, i} R_{f, t-1, i}+B_{2, i}\left(S_{t-1, i}-A_{3, i} F_{t-1, i}\right)+e_{f, t, i} \\
\sigma_{s, t, i}^{2} & =\alpha_{0, i}+\alpha_{1, i} e_{s, t-1, i}^{2}+\alpha_{2, i} \sigma_{s, t-1, i}^{2}+\alpha_{3, i} D_{s, t-1, i} e_{s, t-1, i}^{2}+\alpha_{4, i} \varepsilon_{f, t-1, i}^{2}+\alpha_{5, i} D_{f, t-1, i}^{0} \varepsilon_{f, t-1, i}^{2} \\
& +\alpha_{6, i} S E N T_{t} e_{s, t-1, i}^{2}+\alpha_{7, i} S E N T_{t} \varepsilon_{f, t-1, i}^{2}+\alpha_{8, i} D_{s, t-1, i} S E N T_{t} e_{s, t-1, i}^{2}+\alpha_{9, i} D_{f, t-1, i}^{0} S E N T_{t} \varepsilon_{f, t-1, i}^{2} \\
\sigma_{f, t, i}^{2} & =\beta_{0, i}+\beta_{1, i} e_{f, t-1, i}^{2}+\beta_{2, i} \sigma_{f, t-1, i}^{2}+\beta_{3, i} D_{f, t-1, i} e_{f, t-1, i}^{2}+\beta_{4, i} \varepsilon_{s, t-1, i}^{2}+\beta_{5, i} D_{s, t-1, i}^{0} \varepsilon_{s, t-1, i}^{2} \\
& +\beta_{6, i} S E N T_{t} e_{f, t-1, i}^{2}+\beta_{7, i} S E N T_{t} \varepsilon_{s, t-1, i}^{2}+\beta_{8, i} D_{f, t-1, i} S E N T_{t} e_{f, t-1, i}^{2}+\beta_{9, i} D_{s, t-1, i}^{0} S E N T_{t} \varepsilon_{s, t-1, i}^{2} \\
\sigma_{s f, t, i} & =\left(\gamma_{0, i}+\gamma_{1, i} S E N T_{t}\right) \sigma_{s, t, i} \sigma_{f, t, i} ; \quad \mathrm{i}=1,6 ;
\end{aligned}
$$

Model 2, 3, 4 and 5, impose the following restrictions:

Model 2: $\alpha_{7, i}=\alpha_{8, i}=\alpha_{9, i}=0 ;$ and $\beta_{7, i}=\beta_{8, i}=\beta_{9, i}=0$

Model 3: $\alpha_{6, i}=\alpha_{7, i}=\alpha_{9, i}=0$; and $\beta_{6, i}=\beta_{7, i}=\beta_{9, i}=0$

Model 4: $\alpha_{6, i}=\alpha_{8, i}=\alpha_{9, i}=0 ;$ and $\beta_{6, i}=\beta_{8, i}=\beta_{9, i}=0$

Model 5: $\alpha_{6, i}=\alpha_{7, i}=\alpha_{8, i}=0$; and $\beta_{6, i}=\beta_{7, i}=\beta_{8, i}=0$

\subsection{Results}

\subsubsection{Trading volume analysis}

This paper analyses the impact of investor sentiment on the contemporaneous dynamics of the spot and futures markets and on volatility spillovers between them. The immediate empirical question is whether, as can be deduced from the behavioural finance literature, the level of investor sentiment has a significant impact on the total trading volume in each market. To shed some light on this question, we present an analysis of abnormal trading volume in relation to the level of investor sentiment. In particular, we test for variation in abnormal trading volume in both spot and futures markets at times of high investor sentiment. In addition, because the Engle's test results reveal the presence of $\mathrm{ARCH}$ effects, the variance is modelled by means of a $\operatorname{GARCH}(1,1)$ specification, which takes the following form:

$A V_{t}^{i, m}=\alpha_{i, m}+\beta_{i, m} S E N T_{t}+\gamma_{1, i, m} D_{M}+\gamma_{2, i, m} D_{T}+\gamma_{3, i, m} D_{T h}+\gamma_{4, i, m} D_{F}+\sum_{j=1}^{5} \gamma_{5+j, i, m} A V_{t-j}^{i, m}+e_{t, i, m}$

where $e_{t, i, m}$ follows a $N\left(0, \sigma_{t, i, m}^{2}\right) ; \sigma_{t, i, m}^{2}=\alpha_{0, i, m}+\alpha_{1, i, m} e_{t-1, i, m}^{2}+\alpha_{2, i, m} \sigma_{t-1, i, m}^{2}$

$A V_{t}^{i, m}$ is the abnormal daily trading volume for market $\mathrm{m}$ (spot or futures) and index $i$. As independent variables, we include a dummy (SENT), which takes a value of 1 if investor sentiment is above the median level and 0 otherwise and 4 day-of-the-week dummies $\left(D_{M}, D_{T}, D_{T h}\right.$ and $\left.D_{F}\right)$ which take a value of 1 if it is Monday, Tuesday, Thursday or Friday, respectively and 0 otherwise. The equation is estimated using an AR(5). 
As shown in table 1, Panel A, during periods of high investor sentiment, overall trading volume in spot markets is not significantly affected. The results for the futures market, shown in table 1 , Panel $\mathrm{B}$, show a negative effect which is clearly significant in all indexes considered ${ }^{13}$.

The observed variations in trading volume strengthen the rationale for testing their capacity to trigger changes in price dynamics between spot and futures markets, given the potential impact of such changes on the response of both markets to news. It is also important to emphasize that, while there is no significant change in the level of trading activity in spot markets ${ }^{14}$, it can be seen to decrease significantly in futures markets. This increases market impact costs in futures markets, thereby widening the noarbitrage band.

The results of this test are compatible with behavioural finance arguments; in particular, the "create space" effect. Given that noise traders tend to concentrate in less complex assets, their activities will be more noticeable in spot markets. Furthermore, seeing the market to be overpriced, institutional traders are likely to limit their activity until prices to revert to their fundamentals. Our results indicate that, in spot markets, this reduction is probably offset by an increase in noise trading, while there is no significant change in abnormal trading volume. Due to the absence of this effect in futures markets, abnormal trading volume decreases significantly. It is important to note that, although it is not possible from this analysis to judge whether the investor mix has actually changed in one or both of these markets, the results are compatible with such a possibility ${ }^{15}$. A simple analysis of the case of Eurostoxx50 reveals that the average size of abnormal transactions during periods of high investor sentiment decreases significantly in spot markets while registering no significant change in futures markets ${ }^{16}$. These last results are compatible with some of the papers mentioned above, which report an increase of noise traders and a reduction of institutional trading activity in bullish spot markets. This supports the arguments given above, particularly those concerning the "create space" effect, thereby providing rationale for performing a specific

\footnotetext{
13 The exception is the Spanish index, although this negative effect is significant at a $14 \%$ significance level.

14 Although the results for the Eurostoxx50, the only market for which we have data, suggest a significant change in investor mix due to a higher proportion of noise traders, as predicted by the "create space" effect.

15 It is very difficult to obtain investor trading data for all the markets analysed. Several papers use transaction size to isolate individual from institutional trading activity, however the resulting data are imperfect. In fact, Barclay and Warner (1993) state that, in the presence of informed trading, there is a higher incentive for traders to make medium-size trades in order to camouflage their strategies and thus avoid revealing information (stealth trading), a phenomenon for which several papers have provided evidence (see Blasco et al, 2010).

16 The unavailability of such data in the Datastream database prevents us from providing the results for other markets. The data (number of transactions and trading volume) are drawn from Eurex annual reports on derivative markets (19982013) and from the Nyse-Euronext for the spot market (2004-2013). We compute the monthly average abnormal transaction size (AATS) by deducting the mean of the three previous months. In spot markets, the AATS decreases by $69.35 \%(p=0.097)$, while in futures markets, it increases by $197 \%$ but is not significantly different from zero at conventional significance levels.
} 
analysis of potential change in the contemporaneous correlation and information flow between markets as a result of changes in investor sentiment.

\subsubsection{Impact of investor sentiment on correlation between spot and futures markets}

The estimates from Model 1 are shown in table 2. With respect to the means, it is worth noting the significantly negative sign of the coefficient on the lagged return in all spot and futures markets analysed. Meanwhile, the error correction term parameter is significant in all of the markets. The parameter data for the conditional variance equation show that volatility is affected by own-market shocks ${ }^{17}\left(\alpha_{1}\right.$ and $\left.\beta_{1}\right)$. Both the persistence coefficients $\left(\alpha_{2}\right.$ and $\left.\beta_{2}\right)$ and the asymmetry coefficients ( $\alpha_{3}$ and $\beta_{3}$ ), are positive and significant, with values falling within the usual ranges, thus confirming that negative shocks increase volatility within a given market.

The model also captures other parameters affected by global volatility spillovers and negative shocks. We find that both the parameters involved in global information transfer from the other market $\left(\alpha_{4}\right.$ and $\left.\beta_{4}\right)$ are, as expected, positive and significant overall. In the case of the parameters involved in the asymmetric impact of negative shocks $\left(\alpha_{5}\right.$ and $\left.\beta_{5}\right)$, the results are less clear, although most of them are positive and significant $^{18}$.

In testing test hypothesis $\mathrm{H} 1$, given that the model permits correlation to vary as a function of market sentiment, we need to examine the parameter associated with this change $\left(\gamma_{1}\right)$. The results reveal that, when investor sentiment is high, correlation decreases in all the markets analysed. This decrease is significant at the $1 \%$ level in all cases $^{19}$, thus confirming Hypothesis 1.

This shows that high investor sentiment weakens information efficiency by reducing correlation between markets. The importance of the "create space" effect ${ }^{20}$ can be seen in the observed alterations in trading volume and investor mix in the markets considered, which have ultimately had a significant impact on their correlation ${ }^{21}$. Additionally, any

\footnotetext{
${ }^{17}$ In the case of DAX30 and S\&P500 these parameters are not significantly different from zero.

${ }^{18}$ Note that the figures of these parameters $\left(\alpha_{4}, \alpha_{5}, \beta_{4}\right.$ and $\left.\beta_{5}\right)$ are not comparable to $\left(\alpha_{1}, \alpha_{3}, \beta_{1}\right.$ and $\left.\beta_{3}\right)$ because they are obtained using $\varepsilon_{m, t, i}$ instead of $e_{m, t, i}$.

19 Given the availability of the sentiment indicator affecting the trend of the German market DAX30, we performed a robustness test by repeating the analysis using this measure. Since the findings were practically the same as for the Sentix Eurostoxx50, we decided to adopt the latter for its consistency with other European markets. The results are available from the authors upon request.

${ }^{20}$ Lee et al (2002) report, in this respect, that, when investors are bullish, the "create space" effect dominates the Friedman effect.

${ }^{21}$ Firstly, the significant influx of noise traders to spot markets widens the gap separating them from futures markets in terms of investor mix. In addition, the drop in the proportion of institutional investors in both markets reduces arbitrage
} 
decrease in investor activity, will, in itself, reduce correlation between the two markets because of the direct relationship between trading volume and correlation (see Stoll and Whaley, 1990, Chan, 1992). In the same vein, Bohl et al (2011) show that derivatives and spot markets will correlate increasingly as institutional investors become more active. The reduction in trading volume in futures markets implies a widening of the noarbitrage band, allowing prices to deviate further from equilibrium without giving arbitrageurs incentives to correct them, and reducing contemporaneous correlation between spot and futures prices ${ }^{22}$.

\subsubsection{Effects of investor sentiment on the impact of news on volatility}

Given that the aim of this section is to analyse the effect of sentiment information coming from its own market, the models to be analysed are, specifically, Model 2 and Model 3. The estimates are given in table 3. The variables it shares with Model 1 behave, overall, as described earlier ${ }^{23}$. Observation of the coefficients on the impact of sentiment on information ( $\alpha_{6}$ for the spot market and $\beta_{6}$ for the futures market) shows all of them as negative and significant. The negative sign tells us that, during periods of high investor sentiment, information reaching the market has a lower impact on prices, consistent with over-confidence and self-attribution among uninformed investors, and thus less impact on volatility ${ }^{24}$. Note that this effect may be further strengthened by the effective widening of the no-arbitrage bands. These arguments are confirmed by the results for both types of markets.

The coefficients on the variable used to capture the effect of sentiment on volatility asymmetry $\alpha_{8}$ and $\beta_{8}$ (Model 3) are clearly significant. In fact, all six indexes analysed show a significant decrease in volatility asymmetry in the presence of negative shocks. Once again, we observe this pattern in both types of markets.

This set of results confirms hypothesis H2 and suggests that, when investor sentiment is high, news plays a somewhat less important role in price setting due to the biases of noise traders, the proportion of which is greater in high than low sentiment periods. As expected, this reduction in the role of information is particularly noticeable

\footnotetext{
activity and allows prices to deviate further from their fundamentals. Finally, the reduction in trading activity increases market impact costs, thus widening the no-arbitrage band in the futures market, and lowering the trading incentives of rational investors.

${ }^{22}$ In this line of research, Aragó et al (2003) show that the decrease in transaction costs in the futures markets increases the correlation between spot and futures prices.

23 To save space we show just the coefficients related to investor sentiment.

${ }^{24}$ Note that this effect may be further strengthened by the effective widening of the no-arbitrage bands. These arguments are confirmed by the results for both types of markets.
} 
in the asymmetric effect on volatility, probably as a consequence of noise traders' failure to react to bad news that contradicts their prior beliefs.

The results are therefore in line with the noise trading hypothesis. When sentiment is high, order flow is less informative. Extreme sentiment curbs arbitrage and investor demand reacts not only to changes in fundamentals but also to noise trading, which is intensified by the level of investor sentiment. Note that this is due to noise traders becoming more active than arbitrageurs, especially in the spot market. Driven by overoptimism and overconfidence in their own information, noise traders ignore external information shocks and go on trading regardless, thus lessening the impact of news on volatility and reducing information efficiency.

\subsubsection{Effects of investor sentiment on volatility spillovers}

The next step is to test the effect of sentiment on volatility spillovers, which we do by starting from the unrestricted model described in the previous section and devising two new models, Model 4 which analyses the impact on information coming from the other market and Model 5 which examines the asymmetric effect of that information on volatility.

The estimates are also shown in table 3. Coefficients $\alpha_{7}$ and $\beta_{7}$ (Model 4) capture the impact of sentiment on information coming from the other market. It should be noted that the cross-market shocks considered, including those affected by sentiment, are orthogonal to the information originating in their own markets. As can be seen, when sentiment is high, we find a generalised decrease in cross-market volatility spillovers. In fact, both coefficients in all 6 indexes analysed are highly statistically significant. These results are consistent with those obtained for the effect on own- market volatility. It is also important to note that news can originate not only from the release of exogenous information, but also from that of endogenous information conveyed through trading. If, during periods of high sentiment, there is a drop in trading, there will also be a drop in trading news and, presumably, in the amount of trading news reaching the other market.

Coefficients $\alpha_{9}$ and $\beta_{9}$ (Model 5) associated with the effect of sentiment on the transmission of negative shocks in the spot and futures markets, respectively, are nearly all negatively signed, although significant in FTSE100 futures and the S\&P500 spot market. This means that, in this case, the level of investor sentiment does not affect the asymmetric reaction of volatility to negative shocks coming from the other market. 
These results only partially confirm $\mathrm{H} 3$, since, although, as predicted, we observe that, in periods of high investor sentiment, volatility in one market is less affected by news coming from the other, the decrease in volatility asymmetry following bad news from the other market lacks statistical significance. Again, the results, at least partially, confirm the noise trading hypothesis. The "create space" effect deters arbitrage, which is necessary for informational efficiency, just when the proportion of noise traders is swelling. Informed traders unwilling to increase their risk exposure withdraw from the market, leaving a dominant proportion of uninformed investors trading on their own beliefs, in disregard both of information coming from its own market, but also of information coming from the other market.

Finally, there is minimal variation in any of the findings across the cases analysed, allowing us to conclude that they are robust to possible country-specific institutional or cultural factors, at least in the developed market context in which this paper is situated.

\subsubsection{Robustness checks}

Our purpose in this next section is to analyse the robustness of the results reported above, by examining the sensitivity of our results to four issues: a) extremely bullish sentiment, b) the time horizon for the sentiment measure ${ }^{25}$ c) market status and d) the economic cycle effect in the sentiment proxy.

The first test is to adjust the sentiment dummy in order to check the robustness of the results to its mode of construction. This variable was initially defined to identify a period in which market sentiment had risen above the median level. In this new analysis, the variable is adjusted to capture periods of more extreme levels of sentiment. Taking the top $25 \%$ to be high sentiment periods, the variable takes a value of 1 in these periods and 0 otherwise. Table 4 summarizes the coefficient estimates for this analysis. The results show that cross-market correlation drops significantly during periods of high investor sentiment, thus confirming H1. They also reveal that volatility is less affected by news from either market. At the same time, volatility asymmetry during such periods is found to be less affected by own-market news, while the effect of other-market news remains unchanged. This confirms H2 and partially confirms H3. This consistency with the results of the initial analysis confirms their robustness to the construction of the sentiment variables.

${ }_{25}$ The robustness test will be available only for the Sentix measure, since AAII does not consider horizons of less than 6 months. 
As already stated, the Sentix survey issues two EuroStoxx forecasts; one with a onemonth horizon, and another with a six-month horizon. The second robustness test focuses on sensitivity to the time horizon for the sentiment measure. The results given in the tables shown so far are based on the six-month forecast. However, since the AAII issues only a six-month forecast, we repeated the analysis using the Sentix EuroStoxx one-month forecast. The resulting coefficient estimates, given in table 5, are similar to those reported above, in that high market sentiment triggers a significant decrease in correlation, the reaction of volatility to own-market news (models 2 and 3) and volatility spillovers (models 4 and 5). This clear reduction in correlation allows us to confirm H1. The results for $\mathrm{H} 2$ and $\mathrm{H} 3$, however, differ slightly from those reported in the earlier analyses. Although the impact of news on volatility decreases, as predicted in both these hypotheses, there is a difference in the asymmetric impact of bad news on volatility. While there is barely any significant change in the effect of "own-market" bad news, a large number of the markets analysed show a significant reduction in the impact of "other-market" negative news. This enables confirmation of $\mathrm{H} 3$ and partial confirmation of $\mathrm{H} 2$

Overall, the results obtained, both in terms of correlation and the information effect, show no major variations attributable to the choice of time horizon for estimating the sentiment variable or to its mode of construction, and can therefore be considered highly robust. The only difference worth noting is that which can be observed in the asymmetric impact of news on volatility. When we use the six-month sentiment index, asymmetric volatility decreases only as a reaction to shocks in its own market, whereas, when we use the one-month sentiment index, it is found to decrease in response to news from the other market. These findings confirm the impact of investor sentiment on volatility asymmetry, although the type of information that produces the effect appears to depend on the time horizon.

It is well known that financial assets and financial markets become highly correlated during financial crises (see, among others, Preis et al., 2012 or Krause and Tse, 2013). Also, the effects of volatility are asymmetric over the cycle. As the high and low sentiment times identified may be a reflection of the state of the cycle, our third test is to re-run our models for the tranquil times between 2003 and 2007. As expected, the results obtained persist (see table 6) suggesting that the effects on the joint dynamics of spot and futures markets are due to the effect of investor sentiment.

Finally, given that the sentiment index may include a sentiment component as well as a common economic cycle component, it could be interesting to run the analysis with a 
sentiment measure that explicitly removes the effect of possible changes in the economic cycle. A common solution is to orthogonalise the sentiment proxy to macroeconomic variables (see, among others, Baker and Wurgler, 2006). In our four robustness tests, we analyse the US market for the sake of simplicity. Macroeconomic variables are harder to analyse in the four European markets and the EuroStoxx50 index, because the Sentix survey does not use a homogeneous proportion of participants in all countries. The macroeconomic variables considered are the industrial production index, consumption of durable and non-durable goods and the unemployment rate. The results for the US market are very robust. Correlation between the AAII index and the AAII orthogonal index is 0.93 ( $\mathrm{p}$-value=0.00) and the conclusions obtained for the US market are consistent with those obtained with the non-orthogonal sentiment index. Given that the inclusion of the macroeconomic variables had a negligible effect on the results and due to the difficulty of their consideration in the SentixEuroStoxx 50, they were not considered in our analysis. The results are omitted for reasons of space but can be obtained from the authors on request.

\section{Discussion}

The results described above show that, during periods of high investor sentiment, there are significant changes in the investor mix in financial markets, because the increased presence of noise traders causes sophisticated investors to reduce their risk exposure. This change in investor mix produces different effects in the spot and futures markets, with important repercussions for correlation and information flow between the two. Specifically, a statistically significant decrease in correlation between the two markets is found to occur during periods of high investor sentiment. Although the reduction amounts to no more than $0.1 \%$ to $1 \%$, according to which market we are looking at, apart from the obvious theoretical implications, it is worth analysing whether the decrease in correlation has any economically significant impact.

For a more detailed evaluation of the practical implications, we use a simplified analysis of two phenomena relating directly to changes in correlation between the two markets, namely, hedging effectiveness and futures mispricing.

\subsection{Hedging effectiveness}


The hedge ratio is the ratio of the number of units traded in the futures market to the number of units traded in the spot market. The classic objective of hedging is to minimise the variance of the hedged position of index i at time $\mathrm{t}\left(R_{H, t, i}\right)^{26}$

$\operatorname{Min}\left(\operatorname{Var}\left(R_{H, t, i}\right)\right)=\operatorname{Min} \operatorname{Var}\left(R_{s, t, i}-h_{t} R_{f, t, i}\right)$

where $R_{s, t, i}$ and $R_{f, t, i}$ are the cash and futures return of index i at time t, respectively.

As is well known, the first derivative test gives us:

$h_{t}=\frac{\operatorname{Cov}\left(R_{s, t, i}, R_{f, t, i}\right) / \Omega_{t-1}}{\operatorname{Var}\left(R_{f, t, i}\right) / \Omega_{t-1}}$

where $h_{t}$ is the minimum-variance hedge ratio (MVHR). It is important to note that $\operatorname{Cov}\left(R_{s, t, i}, R_{f, t, i}\right)=\rho_{s, f, t, i} \cdot \sigma\left(R_{s, t, i}\right) \cdot \sigma\left(R_{f, t, i}\right)$, so $h_{t}$ depends on the correlation coefficient between $R_{s, t, i}$ and $R_{f, t, i}\left(\rho_{s, f, t, i}\right)$.

In the case in hand, we have four alternative estimates of $h_{t}$. For the sake of simplicity, and as a benchmark, we consider only Model 1, in which sentiment is included only in the covariance between spot and futures, assuming the absence of direct sentiment effects on the conditional spot and futures variances $\left(h_{t}=h_{t}^{\text {Sent }}\right)$. The alternative estimations are one using the same procedure as in Model 1 but omitting sentiment from the aforementioned spot-futures covariance $\left(h_{t}=h_{t}^{\text {OSent }}\right)$; and two basic models: one using the constant hedging ratio $\left(h_{t}=h\right)$, based on the unconditional variances and covariances between the two series; and one using the naïve hedging ratio, where $h_{t}$ is assumed to be one $\left(h_{t}=1\right)$. Given that this application is intended for explanatory purposes, we simplify the process by performing an in-sample analysis.

For each estimation of $h_{t}$, two transaction-cost assumptions are analysed. The first is a theoretical case, which assumes the absence of transaction costs $(\mathrm{TC}=0)$; the second assumes transaction costs to be small but reasonable marginal costs for institutional investors $(\mathrm{TC}=0.03 \%)^{27}$. Given that, in the zero transaction costs case, $h_{t}$ will probably be different from $h_{t-1}$, the hedge portfolio will be adjusted on a daily basis in the two dynamic hedge strategies ( $h_{t}^{\text {Sent }}$ and $h_{t}^{\text {OSent }}$ ), and kept constant throughout the whole period of analysis in the other two strategies ( $h$ and 1$)$.

\footnotetext{
26 The optimal hedge ratio $(\mathrm{OHR})$ is the ratio that maximises an objective function and the MVHR is the ratio that minimises the variance of the hedging position, although under some conditions, the MVHR is equal to OHR

${ }^{27}$ We have used $0.03 \%$. Note that we do not consider all of the costs for any investor. We consider the marginal trading costs for institutional investors. For example the trading fees for E-mini S\&P500 for equity or clearing members are $\$ 0.35$ per side per contract. These fees are 0.50 Euros for trading Dax30 futures contracts, 0.30 Euros for Eurostoxx 50 futures contracts, 0.15 Euros for CAC40 futures contracts, 0.25 Euros for Ibex35 futures contracts, and 0.20 Pounds Sterling for FTSE 100 futures contracts. In all these cases the marginal costs are below $0.03 \%$.
} 
Under the assumption of transaction costs, the decision whether or not to adjust the hedge ratio is taken on the basis that the aim is to maximise the following utility function ${ }^{28} E\left(R_{H, t}\right)-\lambda \operatorname{Var}\left(R_{H, t}\right)$, where $E\left(R_{H, t}\right)$ is the expected return on the hedged position, $\operatorname{Var}\left(R_{H, t}\right)$ is its variance and $\lambda$ in the investor risk aversion parameter. Assuming $E\left(R_{H, t}\right)$ to be null before transaction costs and a risk-aversion parameter of $4^{29}$, the decision whether or not to adjust hedging is given by the following expression:

$-C T-\lambda\left(\operatorname{Var}\left(R_{s, t}\right)+h_{t}^{2} \operatorname{Var}\left(R_{f, t}\right)-2 h_{t} \operatorname{Cov}\left(R_{s, t}, R_{f, t}\right)\right)>\lambda\left(\operatorname{Var}\left(R_{s, t}\right)+h_{t, *}^{2} \operatorname{Var}\left(R_{f, t}\right)-2 h_{t, *} \operatorname{Cov}\left(R_{s, t}, R_{f, t}\right)\right)$

where $h_{t, *}$ is the last hedge ratio to satisfy condition (7).

As hedging effectiveness measure, Table 7 shows the percentage reduction in the variance $\left(R \operatorname{Var}_{x}\right)$ of the benchmark hedged position using $h_{t}^{\text {Sent }}$ relative to that obtained using the ratio $\mathrm{X}\left(h_{t}^{\text {OSent }}, h\right.$ and 1$)$. Formally:

$$
R \operatorname{Var}_{x}=\frac{\operatorname{Var}\left(R_{H}^{x}\right)-\operatorname{Var}\left(R_{H}^{b}\right)}{\operatorname{Var}\left(R_{H}^{b}\right)}
$$

where $\operatorname{Var}\left(R_{H}^{x}\right)$ is the variance of the hedged position using the hedge ratio $\mathrm{X}\left(h_{t}^{\text {OSent }}, h\right.$ and 1) and $\operatorname{Var}\left(R_{H}^{b}\right)$ is the variance of the hedged position using the dynamic hedge ratio obtained from Model $1\left(h_{t}^{\text {Sent }}\right)$, the model considered as the benchmark model for this analysis.

As can be seen, when sentiment is considered as a relevant variable in spot-futures correlation, the variance of the benchmark hedged position is lower than the variance in the others, albeit not to the same extent across all the markets analysed, where we obtain a reduction in the variance of only $0.03 \%$ in the case of the CAC40, a very similar level for the Eurostoxx50, FTSE and S\&P500, and a slightly higher one for the Dax30 and Ibex35 (0.67\% and $0.77 \%)$. The reductions with respect to the constant hedge ratio (from $0.48 \%$ to $11.59 \%$ ) are considerably greater, and obviously greater again with respect to the Naïve ratio (from $0.84 \%$ to $14.56 \%$ ). To contextualise the results a little more thoroughly, we calculated the percentage reduction in variance of the hedged position with, versus without, sentiment in the dynamic hedge ratio (using $h_{t}^{\text {Sent }}$ instead of $h_{t}^{\text {OSent }}$, that is, $\left.R \operatorname{Var}_{h_{t}^{O S e n t}}\right)$ and compared the results with that obtained using the constant ratio (using $h_{t}^{\text {Sent }}$ instead of $h$, that is, $R \operatorname{Var}_{h}$ ) which takes into account neither sentiment nor changes in the variances and co-variances of the series derived from the

\footnotetext{
${ }^{28}$ See Kroner and Sultan (1993).

${ }_{29}$ This value is commonly found in the literature (see Aragó and Salvador, 2011)
} 
GJR modelling used in the study. This relationship is given by the RIS ratio

$\left(R I S=\frac{R \operatorname{Var}_{h} \text { osent }}{R \operatorname{Var}_{h}}\right)$. It is interesting to observe that the reduction in variance achieved by incorporating sentiment into the dynamic hedging model is between $1.01 \%$ and $80.72 \%$ of that achieved by the constant hedging model. This suggests that the improvement, albeit modest, is not as negligible as a simple interpretation of the initial result might suggest.

As can be expected, the results assuming transaction costs of $0.03 \%$ are less striking overall, because any improvement to be achieved by means of hedge adjustments would not be worth the transaction costs involved. Indeed, if high enough, transaction costs could potentially render spot-futures correlation virtually negligible. In any event, the reduction in the variance of the hedged position using $h_{t}^{\text {Sent }}$ ranges between $0.05 \%$ and $0.97 \%$ and the RIS ratio ranges between $23.86 \%$ and $78.72 \%$.

\subsection{Stock index futures mispricing}

The second application is on mispricing in stock index futures. Having shown that high sentiment raises the proportion of noise traders in the spot market to a very high level, thereby prompting institutional investors to reduce their exposure to noise trading risk (the "create space" effect), we can reasonably assume that this will result in lower market liquidity, lower trading volume and a higher bid-ask spread, due to a decline in arbitrage activity. Given the non-negligible role of the bid-ask spread in market impact costs, any increase in it will mean increased likelihood of mispricing. Thus, if the reasoning is correct, we should see a significant increase in the mispricing of futures contracts in high sentiment periods.

We test this hypothesis by calculating the relative absolute spread of the futures contracts and checking to see if it is significantly higher in periods of high investor sentiment.

The theoretical valuation is based on the cost-of-carry model. The mispricing of futures on index $j$ at time $t M_{j, t}$ is computed as the relative absolute spread between actual futures market prices $F_{j, t}$ and our theoretical cost-of-carry valuation ${ }^{30} F_{j, t}^{C C}$

\footnotetext{
${ }^{30} F_{j, t, T}^{C C}=S_{j, t} \cdot e^{(\delta-q)(T-t)}$, where $\mathrm{t}$ is the current date; $\mathrm{T}$ is the expiration date of the futures contract; $\mathrm{S}_{\mathrm{j}, \mathrm{t}}$ is the price of the underlying asset $\mathrm{j}$ at time $\mathrm{t} ; \delta=\ln (1+\mathrm{i})$, $\mathrm{i}$ is the riskless interest rate; and $\mathrm{q}$ is the dividend yield. For simplicity, we compute the cost-of-carry valuation for the index future at time $t$ using average implied dividends over the period $t-1$ to $t$ 5 . We assume this dividend yield to be a good proxy for the actual dividend yields at time t. In any case, any errors in this procedure are unrelated to the variable of interest (investor sentiment) because they are mainly related with the dividend amounts and dates paid per index component. To proxy for the risk-free interest rate, we use the Euribor 3-month rate for
} 


$$
M_{j, t}=\frac{\left|F_{j, t}-F_{j, t}^{C C}\right|}{F_{j, t}^{C C}}
$$

We use absolute spread because we are interested in any mispricing, whatever the sign. This enables us to cancel out errors with opposite signs. Finally, we use relative absolute spread because it enables us to compare the results through time (2001-2011) and the index showed considerable variations over the sample period.

Table 8 presents the ratios of average mispricing in high sentiment periods to average mispricing in low sentiment periods. In two cases, the CAC40 and the S\&P500, the ratio is less than but very close to 1 . In the case of the Dax30, however, the mispricing of futures is $2.69 \%$ higher in high sentiment periods than in low sentiment periods. The same ratio is $1.23 \%$ in the FTSE and $0.72 \%$ in the Ibex. However, the level of significance is very high in all cases. Thus, we cannot reject the null that mispricing is unrelated to the level of investor sentiment.

It should be noted that, in the above analysis, high/low sentiment is measured as a dummy variable that takes a value of 1 when the index value is above/below the median of the series. This might cancel out mispricing that occurs during low sentiment periods. Nevertheless, since prices deviate from equilibrium in both high and low sentiment periods, we tested for differences in the mispricing of futures in both these contexts (defined as investor sentiment levels above/below the $75^{\text {th }} / 25^{\text {th }}$ percentile of the distribution of the sentiment index being considered) as compared with periods of moderate investor sentiment (between the $25^{\text {th }}$ and $75^{\text {th }}$ percentiles).

Here, the results are considerably clearer. In fact, in extreme sentiment periods, the level of mispricing is between $0.26 \%$ (in the case of the DAX30) and $10.27 \%$ (in that of the CAC40) higher than in periods of moderate sentiment. It is $10.07 \%$ higher in the S\&P500 and 5.02\% higher in the Ibex. In the last three cases, moreover, the differences in relative absolute spread between extreme and moderate sentiment periods are statistically significant.

In summary, our findings in both applications highlight the importance of including investor sentiment in the analysis due to its impact on dynamic spot-futures correlation. Specifically, we have found that it leads to reductions of the variance in the hedged position, which, while small, are far from negligible, needing to be contextualised for each market and time period considered, and allowing no general conclusions to be drawn. Furthermore, the analysis has shown mispricing in futures contracts to be 
related to the level of market sentiment. In particular, it is found that extreme sentiment periods generate significantly higher levels of mispricing than moderate sentiment periods.

The variability between markets detected in the brief analysis performed herein suggests the need for a deeper analysis involving more markets and a diversity of financial development levels, in order to reach more generalisable conclusions. Given that various studies have shown the magnitude of the investor sentiment effect to depend not only on stock characteristics but also on cultural and institutional factors affecting the markets (see Chiou et al, 2010 Chui et al, 2010 or Corredor et al, 2013 among others), the proposed analysis might help to shed new light on classic issues, such as the hedging of portfolios or asset mispricing, among others.

\section{Conclusions}

This study establishes a link between the published research on volatility dynamics and investor sentiment. Through its potential influence on investor behaviour, high sentiment can have a significant impact on correlation between both markets and volatility dynamics. Due to differences in spot and futures market characteristics (investor mix, transaction costs, leverage,...), changes in investor sentiment levels could affect their trading volume, effective transaction costs, and investor mix in different ways and may therefore significantly alter the contemporaneous dynamics between them. To explore this issue, we analyse spot and futures markets on stock market indexes in different countries: the S\&P500 for the US, and a representative set of European indexes (CAC40, DAX30, FTSE100, IBEX35 and Eurostoxx50).

In line with behavioural finance theories, the results of our first analysis have shown that an increased presence of noise traders in the market causes sophisticated investors, faced with an increase in arbitraging risk due to the irrational behaviour of noise traders, and conscious of over-pricing, to reduce their trading activity until prices revert to their fundamentals (by the "create space" effect). Due to the predominance of informed traders in futures markets, an increase in investor sentiment leads to a significant reduction in trading volume, pushing up effective transaction costs and widening the noarbitrage band in all the countries considered. In spot markets, on the other hand, the increase in trading volume brought about by an increase in activity by noise traders is offset by the reduction in the trading activity of informed traders, such that the net effect on trading volume produces no significantly abnormal values. This, however, must not blind us to the fact that, while trading volume remains roughly the same, the investor 
mix in the market in question may have changed considerably. This difference in trading activity and investor mix, which occurs in spot and futures markets as a result of changes in investor sentiment, suggests a possible change in contemporaneous volatility dynamics between the two markets.

Consistent with our expectations, we have shown that the degree of correlation is not stable with the level of investor sentiment. More specifically, the correlation between the two markets diminishes significantly during periods of high investor sentiment. Moreover, the impact of news on volatility in either market is also found to be less significant during these periods (according to the noise trading hypothesis). To a lesser degree, the same can be said of the asymmetric impact of negative shocks on volatility, although it is worth noting that the results are sensitive to the time horizon employed in the estimation of investor sentiment.

The main results obtained are very similar across all the markets analysed, suggesting that cultural and institutional frameworks do not play a crucial role in this issue, or at least not in the developed market context in which this paper is situated. In spite of this homogeneity, the specific results of the effect of sentiment on spot-futures dynamics, and the specific characteristics of futures contracts, fees, etc... can produce economic differences between markets (and probably through time), as shown in the case of hedging effectiveness and, more particularly, the mispricing of futures contracts analysed in the discussion section.

Finally, these findings reveal that the joint dynamics of spot and futures markets is strongly influenced by trading activity and by variables affecting trading behaviour, one of these being investor sentiment.

\section{ACKNOWLEDGEMENTS}

We would like to thank the editor and anonymous referees for their helpful comments. Any errors remaining are the responsibility of the authors. This paper has received financial support from the Spanish Ministry of Science and Innovation (ECO2009-12819) and from the Spanish Ministry of Economy and Competitiveness (ECO2012-35946-C02$01)$.

\section{References}

Antoniou, A. Holmes, P., and Priestley R., (1998) "The effects of stock index futures trading on stock index volatility: an analysis of the asymmetric response of volatility to news”, Journal of Futures Markets, 18, 151-166. 
Aragó, V., Corredor, P., and Santamaría, R., (2003) "Transaction costs, arbitrage, and volatility spillover: a note", International Review of Economics and Finance, 12, 399-415. Aragó V., and Salvador E. (2011) "Sudden changes in variance and time varying hedge ratios" European Journal of Operational Research, 215, 393-403.

Baker, M., and Stein, J., (2004) "Market liquidity as a sentiment indicator", Journal of Financial Markets, 7, 271-299.

Baker, M., and Wurgler, J., (2006) "Investor sentiment and the cross-section of stock returns", Journal of Finance, 61, 1645-1680.

Barberis N., Sheifer A. and Vishny R. (1998) "A model of investor sentiment" Journal of Financial Economics, 49, 307-343.

Barclay M.J., and Warner J.B., (1993) "Stealth trading and volatility" Journal of Financial Economics, 34, 281-305.

Blasco N., Corredor P., and Santamaría R., (2010) "Does informed trading occur in the options market: some revealing clues" Accounting and Finance, 50, 555-579.

Bohl, M.T., Salm, C. A., y Schuppli, M., (2011) "Price discovery and investor structure in stock index futures", Journal of Futures Markets, 31, 282-306.

Brown, G. W., and Cliff, M. T., (2004) "Investor sentiment and the near-term stock market”, Journal of Empirical Finance, 11, 1-27.

Chan, K., (1992) "A further analysis of the lead-lag relationship between the cash market and stock index futures market”, Review of Financial Studies, 5, 123-152.

Chan Y-C. (2014) "How does retail sentiment affect IPO returns? Evidence from the internet bubble period" International Review of Economics and Finance, 29, 235-248.

Chang, Y. Y., Faff, R., and Hwang, C-Y., (2012) "Local and global sentiment effects, and the role of legal, information and trading", Available at SSRN: http://ssrn.com/abstract=1800550 or http://dx.doi.org/10.2139/ssrn.1800550.

Chiou, W-J. P., Lee, A.C., \& Lee, C-F. (2010) Stock return, risk, and legal environment around the world, International Review of Economics and Finance, 19, 95-105.

Chui, A. C. W., Titman, S., \& Wei, K. C. J., (2010) Individualism and momentum around the World, Journal of Finance, 65, 361-392.

Covrig, V. and Ng, L., (2004) "Volume autocorrelation, information and investor trading", Journal of Banking and Finance, 28, 2155-2174.

Corredor, P., Ferrer, E., and Santamaría, R., (2013) "Investor Sentiment Effect in Stock Markets: Stock Characteristics or Country-Specific Factors?" International Review of Economics and Finance, 27, 572-591. 
Cox, C.C. (1976) "Futures trading and market information", Journal of Political Economy, 84, 1215-1237.Daniel, K., Hisrsleifer, D. and Subramanyan, A., (1998) "Investor psychology and security markets under and-overreactions", Journal of Finance, $53,1839-1885$.

De Bondt, W.F.M., (1993) "Betting on trends: intuitive forecasts of financial risk and return", International Journal of Forecasting, 9, 355-371.

De Long, J.B., Shleifer, A., Summers, L.H., and Waldmann, R.J., (1990) "Noise trader risk in financial markets", Journal of Political Economy, 98, 703-738.

Glosten, L.R., Jagannathan, R., and Runkle, D.E., (1993) "On the relation between the expected value and the volatility of the nominal excess return on stocks", Journal of Finance, 48, 1779-1801.

Grossman S.J. and Stiglitz J.E. (1980) "On the impossibility of informationally efficient markets" American Economic Review, 70, 393-408.

Hofstede, G., (2001) “Culture’s Consequences: Comparing Values, Behaviors, Institutions, and Organizations across Nations", Sage Publication, Beverly Hills.

Kavussanos, M.G., Visvikis, I.D., y Alexakis, P.D., (2008) "The lead-lag relationship between cash and stock index futures in a new market", European Financial Management, 14, 1007-1025.

Koutmos, G., and Tucker, M., (1996) "Temporal relationships and dynamic interactions between spot and futures stock markets", Journal of Futures Markets, 16, 55-69.

Krause T, Tse Y. (2013) "Volatility and return spillovers in Canadian and U.S. industry ETFs" International Review of Economics and Finance, 25, 244-259.Kroner, K., Sultan, J., (1993) "Time-varying distributions and dynamic hedging with foreign currency futures". Journal of Financial and Quantitative Analysis 28,.535-551.

La Porta, F., López-de-Silanes, F., Shleifer, A., and Vishny, R.W., (1998) "Law and Finance", Journal of Political Economy, 106, 1113-1155.

Lee, W.Y., Jiang, C.X., and Indro, D.C., (2002) "Spot market volatility, excess returns and the role of investor sentiment", Journal of Banking and Finance, 26, 2277-2299.

Llorente, G. Michaely, R., Saar, G. and Wang, J., (2002) "Dynamic volume-return relation of individual stocks", Review of Finance Studies, 15, 1005-1047.

Peri N., Vandone D., Baldi, L. (2014) "Internet, noise trading and commodity futures prices" International Review of Economics and Finance, 33, 82-89Preis, T., Kenett, D.Y., Stanley, H.E., Helbing, D. and Ben-Jacob, E. (2012) "Quantifying the behavior of stock correlations under market stress" Scientific Reports, 2, 752, 1-5. 
Saha, S. and Chakrabati, G., (2011) "Financial crisis and financial market volatility spill-over" International Journal of Applied Economics and Finance, 5, 185-199.

Shleifer, A. and Summers, L.H., (1990) "The noise trader approach to finance" Journal of Economic Perspectives, 4, 19-33.

Shleifer, A. and Vishny R. (2003) Stock market driven acquisitions, Journal of Financial Economics, 70, 295-311.

Stoll, H. R. and Whaley, R.E., (1990) "The dynamics of stock index and stock index futures returns" Journal of Financial and Quantitative Analysis, 25, 441-468.

Yang C. and Cai C. (2014) "Higher order expectations in sentiment asset pricing model" Economic Modelling, 39, 95-100.

Yang C. and Li. J. (2013) "Investor sentiment, information and asset pricing model" Economic Modelling, 35, 436-442

Yu, J., and Yuan, Y., (2011) "Investor sentiment and the mean-variance relation", Journal of Financial Economics, 100, 367-381. 
Table 1. Effect of sentiment on abnormal volume in the spot and futures markets. 2001-2011

\begin{tabular}{|c|c|c|c|c|c|c|}
\hline & $\mathrm{CAC} 40$ & DAX30 & EUROSTOXX50 & IBEX35 & FTSE100 & S\&P500 \\
\hline$a$ & $0.097^{* * *}$ & $0.056^{* * *}$ & $0.066^{* * *}$ & $0.064^{* * *}$ & $0.057^{* * *}$ & $0.055^{* * *}$ \\
\hline$\beta$ & -0.012 & 0.017 & -0.001 & 0.002 & -0.003 & -0.004 \\
\hline$\gamma_{1}$ & $-0.286^{* * *}$ & $-0.279^{* * *}$ & $-0.236^{* * *}$ & $-0.213^{* * *}$ & $-0.239^{* * *}$ & $-0.142^{* * *}$ \\
\hline$\gamma_{2}$ & -0.012 & -0.026 & -0.015 & -0.019 & $0.027^{* *}$ & -0.007 \\
\hline$\gamma_{3}$ & -0.009 & -0.014 & -0.011 & $-0.036^{* *}$ & $-0.025^{* *}$ & $-0.026^{* * *}$ \\
\hline$\gamma_{4}$ & $-0.050^{* * *}$ & 0.020 & -0.020 & -0.022 & $-0.070^{* * *}$ & $-0.078^{* * *}$ \\
\hline$a_{0}$ & $0.026^{* * *}$ & $0.007^{* * *}$ & $0.036^{* * *}$ & $0.005^{* * *}$ & $0.015^{* * *}$ & $0.010^{* * *}$ \\
\hline$a_{1}$ & $0.249^{* * *}$ & $0.196^{* * *}$ & $0.172^{* * *}$ & $0.048^{* * *}$ & $0.204^{* * *}$ & $0.256^{* * *}$ \\
\hline$a_{2}$ & $0.354^{* * *}$ & $0.749^{* * *}$ & 0.123 & $0.869^{* * *}$ & $0.477^{* * *}$ & $0.380^{* * *}$ \\
\hline \multicolumn{7}{|c|}{ Panel B: Futures Market } \\
\hline & $\mathrm{CAC} 40$ & DAX30 & EUROSTOXX50 & IBEX35 & FTSE100 & S\&P500 \\
\hline$a$ & $0.155^{* * *}$ & $0.099^{* * *}$ & $0.133^{\text {*** }}$ & $0.098^{* * *}$ & 0.026 & $0.044^{* * *}$ \\
\hline$\beta$ & $-0.031^{*}$ & $-0.019^{*}$ & $-0.029^{* *}$ & -0.017 & $-0.029^{* * *}$ & $-0.025^{* *}$ \\
\hline$\gamma_{1}$ & $-0.178^{* * *}$ & $-0.203^{* * *}$ & $-0.271^{* * *}$ & $-0.099^{* * *}$ & $-0.141^{* * *}$ & $-0.161^{* * *}$ \\
\hline$\gamma_{2}$ & $0.079^{* *}$ & 0.019 & 0.041 & $0.105^{* * *}$ & $0.056^{* *}$ & $0.066^{* * *}$ \\
\hline$\gamma_{3}$ & -0.033 & -0.012 & -0.043 & $-0.133^{* * *}$ & -0.007 & $-0.053^{* * *}$ \\
\hline$\gamma_{4}$ & $-0.366^{* * *}$ & $-0.093^{* * *}$ & $-0.229^{* * *}$ & $-0.349^{* * *}$ & $-0.099^{* * *}$ & $-0.087^{* * *}$ \\
\hline$a_{0}$ & $0.074^{* * *}$ & $0.098^{* * *}$ & $0.042^{* * *}$ & $0.061^{*}$ & $0.017^{* * * *}$ & $0.003^{* * *}$ \\
\hline$a_{1}$ & $0.084^{* * *}$ & $0.423^{* * *}$ & $0.062^{* * *}$ & $0.042^{* *}$ & $0.358^{* * *}$ & $0.056^{* * *}$ \\
\hline$a_{2}$ & $0.522^{* * *}$ & 0.081 & $0.600^{* * *}$ & $0.517^{* *}$ & $0.601^{* * *}$ & $0.914^{* * *}$ \\
\hline
\end{tabular}

The sentiment effect (coefficient B) on abnormal trading volume in the spot market (Panel A) and the futures market (Panel B). AV is the abnormal volume of index $\mathrm{i}$ and market $\mathrm{m}$ (spot or futures). SENT is the dummy variable that takes a value of 1 if sentiment is above the median level and 0 otherwise. $\mathrm{D}_{\mathrm{M}}, \mathrm{D}_{\mathrm{T}}, \mathrm{D}_{\mathrm{Th}} \mathrm{y} \mathrm{D}_{\mathrm{F}}$ are dummy variables that take a value of 1 on Mondays, Tuesdays, Thursdays and Fridays, respectively. The estimation includes an $\mathrm{AR}(5)$ process. ${ }^{* * *}$, ** and * indicate $1 \%, 5 \%$, and $10 \%$ levels of significance, respectively.

$A V_{t}^{i, m}=\alpha_{i, m}+\beta_{i, m} S E N T_{t}+\gamma_{1, i, m} D_{M}+\gamma_{2, i, m} D_{T}+\gamma_{3, i, m} D_{T h}++\gamma_{4, i, m} D_{F}+\sum_{j=1}^{5} \gamma_{5+j, i, m} A V_{t-j}^{i, m}+e_{t, i, m}$ where $e_{t, i, m}$ follows a $\mathrm{N}\left(0, \sigma_{t, i, m}^{2}\right) ; \sigma_{t, i, m}^{2}=\alpha_{0, i, m}+\alpha_{1, i, m} e_{t-1, i, m}^{2}+\alpha_{2, i, m} \sigma_{t-1, i, m}^{2}$ 
Table 2. Impact of investor sentiment on the correlation between spot market and futures market (Model 1). 2001-2011

\begin{tabular}{|c|c|c|c|c|c|c|}
\hline & CAC40 & DAX30 & EUROSTOXX50 & FTSE100 & IBEX35 & S\&P500 \\
\hline$A_{0}$ & -0.590 & 0.018 & $0.720^{* *}$ & -0.129 & 0.083 & $1.062^{* *}$ \\
\hline$A_{1}$ & $-0.129^{* * *}$ & $-0.164^{* * *}$ & $-0.214^{* * *}$ & $-0.220^{* * *}$ & $-0.145^{* * *}$ & $-0.194^{* * *}$ \\
\hline$A_{2}$ & 0.127 & 0.006 & $-0.102^{* *}$ & 0.024 & -0.024 & $-0.118^{* *}$ \\
\hline$A_{3}$ & $0.998^{* * *}$ & $0.999^{* * *}$ & $0.991^{* * *}$ & $0.994^{* * *}$ & $0.999^{* * *}$ & $0.987^{* * *}$ \\
\hline$B_{0}$ & -0.944 & $-0.420^{* *}$ & -0.119 & $-0.848^{* *}$ & -0.190 & $-0.899^{*}$ \\
\hline$B_{1}$ & $-0.126^{* *}$ & $-0.151^{* * *}$ & $-0.231^{* * *}$ & $-0.207^{* * *}$ & $-0.145^{\text {***}}$ & $-0.181^{* * *}$ \\
\hline$B_{2}$ & $0.368^{*}$ & $0.366^{* * *}$ & 0.019 & $0.155^{* * *}$ & $0.203^{* * *}$ & $0.099^{*}$ \\
\hline$a_{0}$ & $0.271^{* * *}$ & $0.026^{* * *}$ & $0.049^{* * *}$ & $0.029^{* * *}$ & $0.065^{* * *}$ & $0.013^{* * *}$ \\
\hline$a_{1}$ & $0.019^{* * *}$ & 0.006 & $0.012^{*}$ & $0.016^{* *}$ & $0.046^{* * *}$ & 0.004 \\
\hline$a_{2}$ & $0.722^{* * *}$ & $0.879^{* * *}$ & $0.839^{* * *}$ & $0.891^{* * *}$ & $0.827^{* * *}$ & $0.899^{* * *}$ \\
\hline$a_{3}$ & $0.298^{* * *}$ & $0.122^{* * *}$ & $0.156^{* * *}$ & $0.098^{* * *}$ & $0.109^{* * *}$ & $0.060^{* * *}$ \\
\hline$a_{4}$ & $2.869^{* * *}$ & $0.679^{* * *}$ & $0.550^{* * *}$ & $0.398^{* * *}$ & $1.275^{* * *}$ & $0.320^{* * *}$ \\
\hline$a_{5}$ & $-0.774^{*}$ & $0.654^{* * *}$ & $0.211^{* *}$ & -0.060 & 0.294 & $0.086^{* * *}$ \\
\hline$\beta_{0}$ & $0.283^{* * *}$ & $0.027^{* * *}$ & $0.050^{* * *}$ & $0.027^{* * *}$ & $0.069^{* * *}$ & $0.016^{* * *}$ \\
\hline$\beta_{1}$ & $0.027^{* * *}$ & 0.002 & $0.017^{* *}$ & $0.019^{* * *}$ & $0.051^{* * *}$ & -0.005 \\
\hline$\beta_{2}$ & $0.709^{* * *}$ & $0.879^{* * *}$ & $0.828^{* * *}$ & $0.890^{* * *}$ & $0.815^{* * *}$ & $0.906^{\text {***}}$ \\
\hline$\beta_{3}$ & $0.285^{* * *}$ & $0.118^{* * *}$ & $0.106^{* * *}$ & 0.002 & $0.110^{* * *}$ & $0.153^{* * *}$ \\
\hline$\beta_{4}$ & $2.362^{* * *}$ & $0.945^{* * *}$ & $0.960^{* * *}$ & $0.326^{* * *}$ & $1.707^{* * *}$ & $0.166^{* * *}$ \\
\hline$\beta_{5}$ & $0.627^{* * *}$ & 0.010 & $0.044^{*}$ & $0.091^{* * *}$ & $0.316^{*}$ & $0.058^{*}$ \\
\hline$\gamma_{0}$ & $0.990^{* * *}$ & $0.983^{* * *}$ & $0.969^{* * *}$ & $0.980^{* * *}$ & $0.989^{* * *}$ & $0.982^{* * *}$ \\
\hline$\gamma_{1}$ & $-0.001^{* * * *}$ & $-0.009^{* * *}$ & $-0.004^{* * *}$ & $-0.004^{* * *}$ & $-0.001^{* * *}$ & $-0.008^{* * *}$ \\
\hline
\end{tabular}

Model 1

$R_{s, t, i}=A_{0, i}+A_{1, i} R_{s, t-1, i}+A_{2, i}\left(S_{t-1, i}-A_{3, i} F_{t-1, i}\right)+e_{s, t, i}$

$R_{f, t, i}=B_{0, i}+B_{1, i} R_{f, t-1, i}+B_{2, i}\left(S_{t-1, i}-A_{3, i} F_{t-1, i}\right)+e_{f, t, i}$

$\sigma_{s, t, i}^{2}=\alpha_{0, i}+\alpha_{1, i} e_{s, t-1, i}^{2}+\alpha_{2, i} \sigma_{s, t-1, i}^{2}+\alpha_{3, i} D_{s, t-1, i} e_{s, t-1, i}^{2}+\alpha_{4, i} \varepsilon_{f, t-1, i}^{2}+\alpha_{5, i} D_{f, t-1, i}^{0} \varepsilon_{f, t-1, i}^{2}$

$\sigma_{f, t, i}^{2}=\beta_{0, i}+\beta_{1, i} e_{f, t-1, i}^{2}+\beta_{2, i} \sigma_{f, t-1, i}^{2}+\beta_{3, i} D_{f, t-1, i} e_{f, t-1, i}^{2}+\beta_{4, i} \varepsilon_{s, t-1, i}^{2}+\beta_{5, i} D_{s, t-1, i}^{0} \varepsilon_{s, t-1, i}^{2}$

$\sigma_{s f, t, i}=\left(\gamma_{0, i}+\gamma_{1, i} S E N T_{t}\right) \sigma_{s, t, i} \sigma_{f, t, i} ; \quad \mathrm{i}=1,6$

where $\left(S_{t-1, i}-A_{3, i} F_{t-1, i}\right)$ is the error correction term imposing the long-term equilibrium on index $i$ in the two markets; $e_{s, t, i}\left(e_{f, t, i}\right)$ is the innovation in the spot (futures) market at day $t$ for index $i$; $\sigma_{s, t, i}^{2}=\operatorname{var}\left(e_{s, t, i} / \Omega_{\mathrm{t}-1, \mathrm{i}}\right)$ is the conditional variance of the spot market and $\sigma_{f, t, i}^{2}=\operatorname{var}\left(e_{f, t, i} / \Omega_{\mathrm{t}-1, \mathrm{i}}\right)$ is the conditional variance of the futures market, where $\Omega_{\mathrm{t}, \mathrm{i}}$ is the information set available at $\mathrm{t}$ for index $i . \sigma_{s f, t, i}$ is the conditional covariance between spot and futures markets. The innovation $\varepsilon_{s, t, i}\left(\varepsilon_{f, t, i}\right)$ is the information from the spot (futures) market which is transmitted to the futures (spot) market and is not included in $e_{f, t, i}\left(e_{s, t, i}\right)$. The dummy variable SENT has a value of 1 if sentiment is above the median level and 0 otherwise. We use the Sentix 6 month-ESX 50 Index as the sentiment proxy for the European indices and AAII for the US index. The dummy variable $D_{s, t, i}\left(D_{f, t, i}\right)$ is equal to 1 if $e_{s, t, i}\left(e_{f, t, i}\right)<0$. The dummy variable $D_{s, t, i}^{0}\left(D_{f, t, i}^{0}\right)$ is equal to 1 if $\varepsilon_{s, t, i}\left(\varepsilon_{f, t, i}\right)<0 . * * * * *$ and *indicate $1 \%, 5 \%$, and $10 \%$ levels of significance, respectively. 
Table 3. Effect of investor sentiment on spot (futures) volatility (Model 2), on asymmetries in spot (futures) volatility (Model 3). on volatility spillovers (Model 4) and on asymmetries in spot (futures) volatility spillovers (Model 5). 2001-2011

\begin{tabular}{|c|c|c|c|c|c|c|}
\hline \multirow[b]{2}{*}{ Coeff. } & $\mathrm{CAC} 40$ & DAX30 & EUROSTOXX50 & FTSE100 & IBEX35 & S\&P500 \\
\hline & \multicolumn{6}{|c|}{ Model 2} \\
\hline$a_{6}$ & $-0.016^{* * *}$ & $-0.016^{* * *}$ & $-0.021^{* * *}$ & $-0.017^{* * *}$ & $-0.012^{* * *}$ & $-0.038^{* * *}$ \\
\hline$\beta_{6}$ & $-0.015^{*}$ & $-0.018^{* * *}$ & $-0.019^{* \star * *}$ & $-0.021^{* * *}$ & $-0.009^{* * * *}$ & $-0.031^{* * *}$ \\
\hline \multirow[t]{2}{*}{$\gamma_{1}$} & $-0.001^{* * *}$ & $-0.010^{* * * *}$ & $-0.006^{* * *}$ & $-0.005^{* * *}$ & $-0.002^{* * *}$ & $-0.009^{* * *}$ \\
\hline & \multicolumn{6}{|c|}{ Model 3} \\
\hline$a_{8}$ & $-0.190^{* * *}$ & $-0.044^{* * *}$ & $-0.027^{*}$ & $-0.050^{* * *}$ & $-0.114^{* * *}$ & $-0.076^{* * *}$ \\
\hline$\beta_{8}$ & $-0.083^{* * *}$ & $-0.074^{* * *}$ & $-0.046^{* * *}$ & $-0.073^{* * *}$ & $-0.049^{* * *}$ & $-0.059^{* * *}$ \\
\hline \multirow[t]{2}{*}{$\gamma_{1}$} & $-0.002^{* * *}$ & $-0.010^{* * *}$ & $-0.005^{* * *}$ & $-0.006^{* * *}$ & $-0.003^{* * *}$ & $-0.009^{* * *}$ \\
\hline & \multicolumn{6}{|c|}{ Model 4} \\
\hline$a_{7}$ & $-0.734^{* * *}$ & $-0.718^{* * *}$ & $-0.579^{* * *}$ & $-0.3419^{* * *}$ & $-1.029^{* * *}$ & $-0.136^{* * *}$ \\
\hline$\beta_{7}$ & $-1.021^{* * *}$ & $-0.662^{* * *}$ & $-0.889^{* * *}$ & $-0.408^{* * *}$ & $-1.134^{* * *}$ & -0.067 \\
\hline \multirow[t]{2}{*}{$\gamma_{1}$} & $-0.002^{* * *}$ & $-0.012^{* * *}$ & $-0.012^{* * *}$ & $-0.007^{* * *}$ & $-0.002^{* * *}$ & $-0.008^{* * *}$ \\
\hline & \multicolumn{6}{|c|}{ Model 5} \\
\hline$a_{9}$ & 0.156 & -0.002 & -0.034 & 0.054 & -0.042 & $-0.017^{* * *}$ \\
\hline$\beta_{9}$ & -0.213 & -0.005 & -0.006 & $-0.009^{* *}$ & 0.107 & 0.012 \\
\hline$\gamma_{1}$ & $-0.001^{* * *}$ & $-0.009^{* * *}$ & $-0.004^{* * *}$ & $-0.005^{* * *}$ & $-0.001^{* * *}$ & $-0.008^{* * *}$ \\
\hline
\end{tabular}

Unrestricted Model:

$$
\begin{aligned}
& R_{s, t, i}=A_{0, i}+A_{1, i} R_{s, t-1, i}+A_{2, i}\left(S_{t-1, i}-A_{3, i} F_{t-1, i}\right)+e_{s, t, i} \\
& R_{f, t, i}=B_{0, i}+B_{1, i} R_{f, t-1, i}+B_{2, i}\left(S_{t-1, i}-A_{3, i} F_{t-1, i}\right)+e_{f, t, i} \\
& \sigma_{s, t, i}^{2}=\alpha_{0, i}+\alpha_{1, i} e_{s, t-1, i}^{2}+\alpha_{2, i} \sigma_{s, t-1, i}^{2}+\alpha_{3, i} D_{s, t-1, i} e_{s, t-1, i}^{2}+\alpha_{4, i} \varepsilon_{f, t-1, i}^{2}+\alpha_{5, i} D_{f, t-1, i}^{0} \varepsilon_{f, t-1, i}^{2} \\
& +\alpha_{6, i} \operatorname{SENT}_{t} e_{s, t-1, i}^{2}+\alpha_{7, i} \operatorname{SENT}_{t} \varepsilon_{f, t-1, i}^{2}+\alpha_{8, i} D_{s, t-1, i} \operatorname{SENT}_{t} e_{s, t-1, i}^{2}+\alpha_{9, i} D_{f, t-1, i}^{0} \operatorname{SENT}_{t} \varepsilon_{f, t-1, i}^{2} \\
& \sigma_{f, t, i}^{2}=\beta_{0, i}+\beta_{1, i} e_{f, t-1, i}^{2}+\beta_{2, i} \sigma_{f, t-1, i}^{2}+\beta_{3, i} D_{f, t-1, i} e_{f, t-1, i}^{2}+\beta_{4, i} \varepsilon_{s, t-1, i}^{2}+\beta_{5, i} D_{s, t-1, i}^{0} \varepsilon_{s, t-1, i}^{2} \\
& +\beta_{6, i} \operatorname{SENT}_{t} e_{f, t-1, i}^{2}+\beta_{7, i} \operatorname{SENT}_{t} \varepsilon_{s, t-1, i}^{2}+\beta_{8, i} D_{f, t-1, i} \operatorname{SENT}_{t} e_{f, t-1, i}^{2}+\beta_{9, i} D_{s, t-1, i}^{0} \operatorname{SENT}_{t} \varepsilon_{s, t-1, i}^{2} \\
& \sigma_{s f, t, i}=\left(\gamma_{0, i}+\gamma_{1, i} S E N T_{t}\right) \sigma_{s, t, i} \sigma_{f, t, i} ; \quad \mathrm{i}=1,6 \text {; } \\
& \text { Model 2: } \alpha_{7, i}=\alpha_{8, i}=\alpha_{9, i}=0 ; \text { and } \beta_{7, i}=\beta_{8, i}=\beta_{9, i}=0 \\
& \text { Model 3: } \alpha_{6, i}=\alpha_{7, i}=\alpha_{9, i}=0 \text {; and } \beta_{6, i}=\beta_{7, i}=\beta_{9, i}=0 \\
& \text { Model 4: } \alpha_{6, i}=\alpha_{8, i}=\alpha_{9, i}=0 ; \text { and } \beta_{6, i}=\beta_{8, i}=\beta_{9, i}=0 \\
& \text { Model 5: } \alpha_{6, i}=\alpha_{7, i}=\alpha_{8, i}=0 \text {; and } \beta_{6, i}=\beta_{7, i}=\beta_{8, i}=0 \\
& \text { where }\left(S_{t-1, i}-A_{3, i} F_{t-1, i}\right) \text { is the error correction term imposing the long-term equilibrium on index } i \text { in the } \\
& \text { two markets; } e_{s, t, i}\left(e_{f, t, i}\right) \text { is the innovation in the spot (futures) market at day } t \text { for index } i \text {; } \\
& \sigma_{s, t, i}^{2}=\operatorname{var}\left(e_{s, t, i} / \Omega_{\mathrm{t}-1, \mathrm{i}}\right) \text { is the conditional variance of the spot market and } \sigma_{f, t, i}^{2}=\operatorname{var}\left(e_{f, t, i} / \Omega_{\mathrm{t}-1, \mathrm{i}}\right) \text { is the }
\end{aligned}
$$


Table 4. Effect of extremely bullish sentiment on correlation between markets and on volatility spillovers, Six-month Sentix index and AAII. 2001-2011

\begin{tabular}{|c|c|c|c|c|c|c|}
\hline \multirow[b]{2}{*}{ Coeff. } & $\mathrm{CAC} 40$ & DAX30 & EUROSTOXX50 & FTSE100 & IBEX35 & S\&P500 \\
\hline & \multicolumn{6}{|c|}{ Model 2} \\
\hline$a_{6}$ & $-0.039^{* * *}$ & $-0.038^{* * *}$ & $-0.045^{* * *}$ & $-0.049^{* * *}$ & $-0.043^{* * *}$ & $-0.028^{* * *}$ \\
\hline$\beta_{6}$ & $-0.041^{* * *}$ & $-0.040^{* * *}$ & $-0.047^{* * *}$ & $-0.058^{* * *}$ & $-0.042^{* * *}$ & $-0.026^{* * *}$ \\
\hline \multirow[t]{2}{*}{$\gamma_{1}$} & $-0.002^{* * *}$ & $-0.013^{* * *}$ & $-0.013^{* * *}$ & $-0.011^{* * *}$ & $-0.001^{* *}$ & $-0.016^{* * *}$ \\
\hline & \multicolumn{6}{|c|}{ Model 3} \\
\hline$a_{8}$ & $-0.071^{* * *}$ & $-0.066^{* * *}$ & $-0.036^{* * *}$ & $-0.058^{* * *}$ & $-0.052^{* *}$ & $-0.076^{* * *}$ \\
\hline$\beta_{8}$ & $-0.083^{* * *}$ & $-0.074^{* * *}$ & $-0.046^{* * *}$ & $-0.073^{* * *}$ & $-0.049^{* * *}$ & $-0.059^{* * *}$ \\
\hline$\gamma_{1}$ & $-0.001^{* * *}$ & $-0.012^{* * *}$ & $-0.009^{* * *}$ & $-0.007^{* * *}$ & -0.001 & $-0.017^{* * *}$ \\
\hline & \multicolumn{6}{|c|}{ Model 4} \\
\hline$\alpha_{7}$ & $-0.523^{*}$ & $-0.606^{* * *}$ & $-0.528^{* * *}$ & $-0.342^{* * *}$ & $-0.956^{* * *}$ & 0.088 \\
\hline$\beta_{7}$ & $-0.074^{* * *}$ & $-0.636^{* * *}$ & $-0.920^{* * *}$ & $-0.376^{\text {****}}$ & $-1.162^{* * *}$ & 0.077 \\
\hline$\gamma_{1}$ & $-0.001^{* * *}$ & $-0.015^{* * *}$ & $-0.017^{* * *}$ & $-0.008^{* * *}$ & $-0.001^{*}$ & $-0.013^{* * *}$ \\
\hline & \multicolumn{6}{|c|}{ Model 5} \\
\hline$\alpha_{9}$ & -0.363 & 0.021 & -0.041 & $-0.169^{*}$ & $-0.345^{* *}$ & $-0.019^{* * *}$ \\
\hline$\beta_{9}$ & -0.978 & -0.011 & -0.016 & $-0.025^{* * *}$ & $-0.648^{* * *}$ & 0.021 \\
\hline$\gamma_{1}$ & $-0.001^{* * *}$ & $-0.010^{* * *}$ & $-0.008^{* * *}$ & $-0.007^{* * *}$ & 0.000 & $-0.013^{* * *}$ \\
\hline
\end{tabular}

Unrestricted Model:

$$
\begin{aligned}
& R_{s, t, i}=A_{0, i}+A_{1, i} R_{s, t-1, i}+A_{2, i}\left(S_{t-1, i}-A_{3, i} F_{t-1, i}\right)+e_{s, t, i} \\
& R_{f, t, i}=B_{0, i}+B_{1, i} R_{f, t-1, i}+B_{2, i}\left(S_{t-1, i}-A_{3, i} F_{t-1, i}\right)+e_{f, t, i} \\
& \sigma_{s, t, i}^{2}=\alpha_{0, i}+\alpha_{1, i} e_{s, t-1, i}^{2}+\alpha_{2, i} \sigma_{s, t-1, i}^{2}+\alpha_{3, i} D_{s, t-1, i} e_{s, t-1, i}^{2}+\alpha_{4, i} \varepsilon_{f, t-1, i}^{2}+\alpha_{5, i} D_{f, t-1, i}^{0} \varepsilon_{f, t-1, i}^{2} \\
& +\alpha_{6, i} \operatorname{SENT}_{t} e_{s, t-1, i}^{2}+\alpha_{7, i} \operatorname{SENT}_{t} \varepsilon_{f, t-1, i}^{2}+\alpha_{8, i} D_{s, t-1, i} \operatorname{SENT}_{t} e_{s, t-1, i}^{2}+\alpha_{9, i} D_{f, t-1, i}^{0} \operatorname{SENT}_{t} \varepsilon_{f, t-1, i}^{2} \\
& \sigma_{f, t, i}^{2}=\beta_{0, i}+\beta_{1, i} e_{f, t-1, i}^{2}+\beta_{2, i} \sigma_{f, t-1, i}^{2}+\beta_{3, i} D_{f, t-1, i} e_{f, t-1, i}^{2}+\beta_{4, i} \varepsilon_{s, t-1, i}^{2}+\beta_{5, i} D_{s, t-1, i}^{0} \varepsilon_{s, t-1, i}^{2} \\
& +\beta_{6, i} \operatorname{SENT}_{t} e_{f, t-1, i}^{2}+\beta_{7, i} \operatorname{SENT}_{t} \varepsilon_{s, t-1, i}^{2}+\beta_{8, i} D_{f, t-1, i} \operatorname{SENT}_{t} e_{f, t-1, i}^{2}+\beta_{9, i} D_{s, t-1, i}^{0} \operatorname{SENT}_{t} \varepsilon_{s, t-1, i}^{2} \\
& \sigma_{s f, t, i}=\left(\gamma_{0, i}+\gamma_{1, i} S E N T_{t}\right) \sigma_{s, t, i} \sigma_{f, t, i} ; \quad \mathrm{i}=1,6 \text {; }
\end{aligned}
$$

where $\left(S_{t-1, i}-A_{3, i} F_{t-1, i}\right)$ is the error correction term imposing the long-term equilibrium on index $i$ in the two markets; $e_{s, t, i}\left(e_{f, t, i}\right)$ is the innovation in the spot (futures) market at day $t$ for index $i$; $\sigma_{s, t, i}^{2}=\operatorname{var}\left(e_{s, t, i} / \Omega_{\mathrm{t}-1, \mathrm{i}}\right)$ is the conditional variance of the spot market and $\sigma_{f, t, i}^{2}=\operatorname{var}\left(e_{f, t, i} / \Omega_{\mathrm{t}-1, \mathrm{i}}\right)$ is the conditional variance of the futures market, where $\Omega_{\mathrm{t}, \mathrm{i}}$ is the information set available at $\mathrm{t}-1$ for index $i$. $\sigma_{s f, t, i}$ is the conditional covariance between spot and futures markets. The innovation $\varepsilon_{s, t, i}\left(\varepsilon_{f, t, i}\right)$ is the information from the spot (futures) market which is transmitted to the futures (spot) market and is not included in $e_{f, t, i}\left(e_{s, t, i}\right)$.The dummy variable SENT has a value of 1 for sentiment scores within the top $25 \%$ and 0 otherwise. We use the Sentix 6 month-ESX 50 Index as the sentiment proxy for the European indices and AAII for the US index. The dummy variable $D_{s, t, i}\left(D_{f, t, i}\right)$ is equal to 1 if $e_{s, t, i}\left(e_{f, t, i}\right)<0$. The dummy variable $D_{s, t, i}^{0}\left(D_{f, t, i}^{0}\right)$ is equal to 1 if $\varepsilon_{s, t, i}\left(\varepsilon_{f, t, i}\right)<0 .{ }^{* * *},{ }^{* *}$ and *indicate $1 \%, 5 \%$, and $10 \%$ levels of significance, respectively. 
Table 5. Effect of sentiment on correlation between markets and on volatility spillovers, One-month Sentix index. 2001-2011

\begin{tabular}{|c|c|c|c|c|c|}
\hline & $\mathrm{CAC} 40$ & DAX30 & EUROSTOXX50 & FTSE100 & IBEX35 \\
\hline Coeff. & \multicolumn{5}{|c|}{ Model 2} \\
\hline$a_{6}$ & 0.111 & -0.007 & $-0.039^{* * *}$ & $-0.009^{*}$ & 0.010 \\
\hline$\beta_{6}$ & 0.119 & $-0.018^{* * *}$ & $-0.054^{* * *}$ & $-0.011^{* *}$ & 0.005 \\
\hline \multirow[t]{2}{*}{$\gamma_{1}$} & $-0.002^{* * *}$ & $-0.007^{* * *}$ & $-0.013^{* * *}$ & $-0.012^{* * *}$ & $-0.004^{* * *}$ \\
\hline & \multicolumn{5}{|c|}{ Model 3} \\
\hline$a_{8}$ & $-0.269^{* * *}$ & -0.005 & $-0.076^{* * *}$ & 0.011 & 0.008 \\
\hline$\beta_{8}$ & $-0.271^{* * *}$ & -0.015 & $-0.093^{* * *}$ & 0.009 & 0.004 \\
\hline \multirow[t]{2}{*}{$\gamma_{1}$} & $-0.003^{* * *}$ & $-0.007^{* * *}$ & $-0.012^{* * *}$ & $-0.011^{* * *}$ & $-0.004^{* * *}$ \\
\hline & \multicolumn{5}{|c|}{ Model 4} \\
\hline$\alpha_{7}$ & -0.247 & $-0.647^{* * *}$ & -0.090 & $-0.362^{* * *}$ & $-1.602^{* * *}$ \\
\hline$\beta_{7}$ & $-0.483^{*}$ & $-0.758^{* * *}$ & $-0.273^{* *}$ & $-0.364^{* * *}$ & $-1.824^{* * *}$ \\
\hline \multirow[t]{2}{*}{$\gamma_{1}$} & $-0.003^{* * *}$ & $-0.009^{* * *}$ & $-0.012^{* * *}$ & $-0.013^{* * *}$ & $-0.005^{* * *}$ \\
\hline & \multicolumn{5}{|c|}{ Model 5} \\
\hline$\alpha_{9}$ & -0.096 & $0.303^{* *}$ & 0.084 & $-0.256^{* * *}$ & $-0.181^{* * *}$ \\
\hline$\beta_{9}$ & $-0.749^{* * *}$ & -0.004 & -0.018 & $-0.011^{* *}$ & $-0.159^{* *}$ \\
\hline$\gamma_{1}$ & $-0.003^{* * *}$ & $-0.007^{* * *}$ & $-0.010^{* * *}$ & $-0.011^{* * *}$ & $-0.004^{* * *}$ \\
\hline
\end{tabular}

Unrestricted Model:

$$
\begin{aligned}
& R_{s, t, i}=A_{0, i}+A_{1, i} R_{s, t-1, i}+A_{2, i}\left(S_{t-1, i}-A_{3, i} F_{t-1, i}\right)+e_{s, t, i} \\
& R_{f, t, i}=B_{0, i}+B_{1, i} R_{f, t-1, i}+B_{2, i}\left(S_{t-1, i}-A_{3, i} F_{t-1, i}\right)+e_{f, t, i} \\
& \sigma_{s, t, i}^{2}=\alpha_{0, i}+\alpha_{1, i} e_{s, t-1, i}^{2}+\alpha_{2, i} \sigma_{s, t-1, i}^{2}+\alpha_{3, i} D_{s, t-1, i} e_{s, t-1, i}^{2}+\alpha_{4, i} \varepsilon_{f, t-1, i}^{2}+\alpha_{5, i} D_{f, t-1, i}^{0} \varepsilon_{f, t-1, i}^{2} \\
& +\alpha_{6, i} \operatorname{SENT}_{t} e_{s, t-1, i}^{2}+\alpha_{7, i} \operatorname{SENT}_{t} \varepsilon_{f, t-1, i}^{2}+\alpha_{8, i} D_{s, t-1, i} \operatorname{SENT}_{t} e_{s, t-1, i}^{2}+\alpha_{9, i} D_{f, t-1, i}^{0} \operatorname{SENT}_{t} \varepsilon_{f, t-1, i}^{2} \\
& \sigma_{f, t, i}^{2}=\beta_{0, i}+\beta_{1, i} e_{f, t-1, i}^{2}+\beta_{2, i} \sigma_{f, t-1, i}^{2}+\beta_{3, i} D_{f, t-1, i} e_{f, t-1, i}^{2}+\beta_{4, i} \varepsilon_{s, t-1, i}^{2}+\beta_{5, i} D_{s, t-1, i}^{0} \varepsilon_{s, t-1, i}^{2} \\
& +\beta_{6, i} \operatorname{SENT}_{t} e_{f, t-1, i}^{2}+\beta_{7, i} \operatorname{SENT}_{t} \varepsilon_{s, t-1, i}^{2}+\beta_{8, i} D_{f, t-1, i} \operatorname{SENT}_{t} e_{f, t-1, i}^{2}+\beta_{9, i} D_{s, t-1, i}^{0} \operatorname{SENT}_{t} \varepsilon_{s, t-1, i}^{2} \\
& \sigma_{s f, t, i}=\left(\gamma_{0, i}+\gamma_{1, i} S E N T_{t}\right) \sigma_{s, t, i} \sigma_{f, t, i} ; \quad \mathrm{i}=1,6 \text {; }
\end{aligned}
$$

where $\left(S_{t-1, i}-A_{3, i} F_{t-1, i}\right)$ is the error correction term imposing the long-term equilibrium on index $i$ in the two markets; $e_{s, t, i}\left(e_{f, t, i}\right)$ is the innovation in the spot (futures) market at day $t$ for index $i$; $\sigma_{s, t, i}^{2}=\operatorname{var}\left(e_{s, t, i} / \Omega_{\mathrm{t}-1, \mathrm{i}}\right)$ is the conditional variance of the spot market and $\sigma_{f, t, i}^{2}=\operatorname{var}\left(e_{f, t, i} / \Omega_{\mathrm{t}-1, \mathrm{i}}\right)$ is the conditional variance of the futures market, where $\Omega_{\mathrm{t}, \mathrm{i}}$ is the information set available at $\mathrm{t}-1$ for index $i$. $\sigma_{s f, t, i}$ is the conditional covariance between spot and futures markets. The innovation $\varepsilon_{s, t, i}\left(\varepsilon_{f, t, i}\right)$ is the information from the spot (futures) market which is transmitted to the futures (spot) market and is not included in $e_{f, t, i}\left(e_{s, t, i}\right)$.The dummy variable SENT has a value of 1 if sentiment is above the median level and 0 otherwise. We use the Sentix 1 month-ESX 50 Index as the sentiment proxy for the European indices. The dummy variable $D_{s, t, i}\left(D_{f, t, i}\right)$ is equal to 1 if $e_{s, t, i} \quad\left(e_{f, t, i}\right)<0$. The dummy variable $D_{s, t, i}^{0}\left(D_{f, t, i}^{0}\right)$ is equal to 1 if $\varepsilon_{s, t, i}\left(\varepsilon_{f, t, i}\right)<0 . * * * * *$ and *indicate $1 \%, 5 \%$, and $10 \%$ levels of significance, respectively. 
Table 6. Effect of sentiment on correlation between markets and on volatility spillovers, 2003-2007

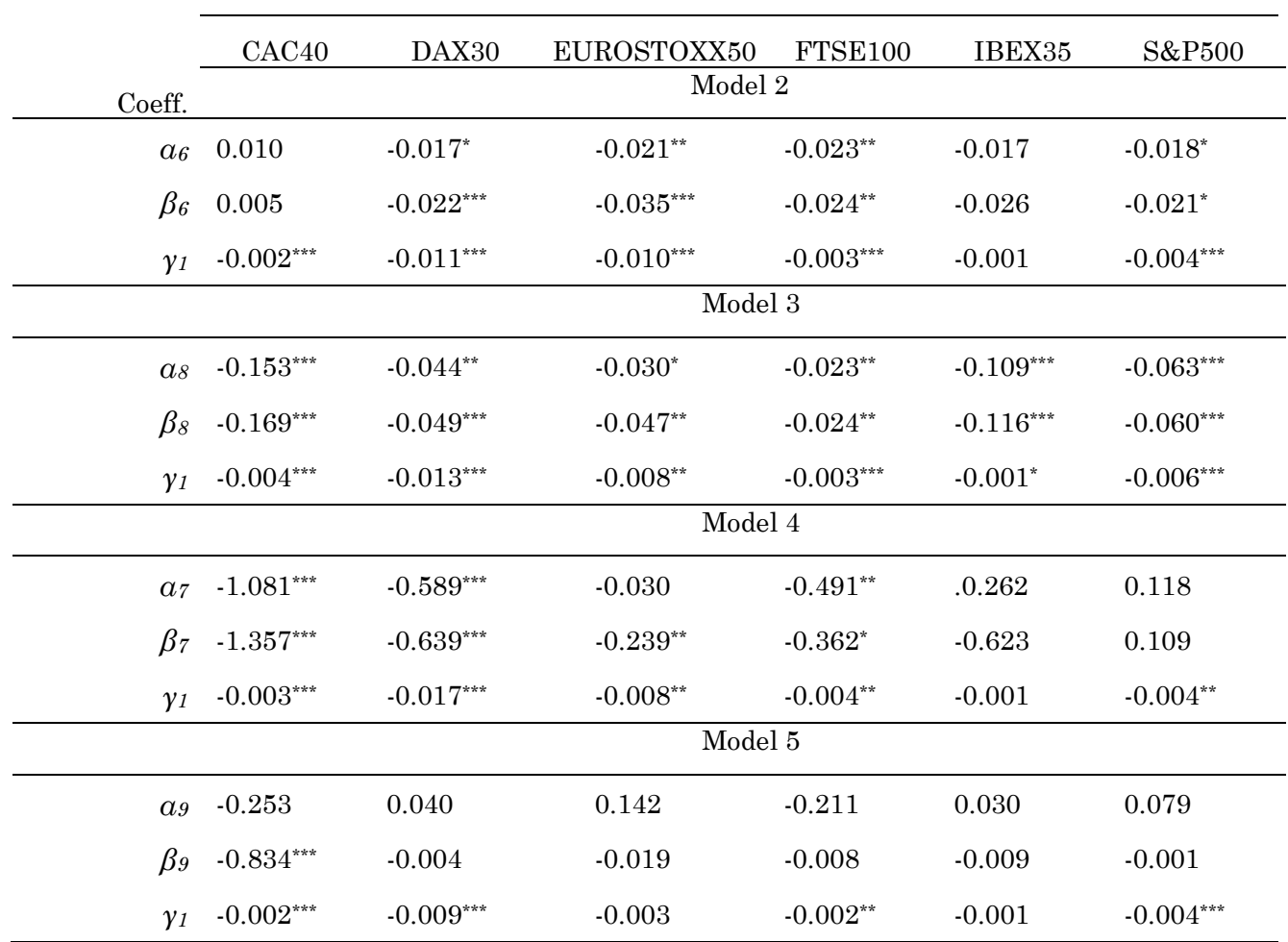

Unrestricted Model:

$$
\begin{aligned}
& R_{s, t, i}=A_{0, i}+A_{1, i} R_{s, t-1, i}+A_{2, i}\left(S_{t-1, i}-A_{3, i} F_{t-1, i}\right)+e_{s, t, i} \\
& R_{f, t, i}=B_{0, i}+B_{1, i} R_{f, t-1, i}+B_{2, i}\left(S_{t-1, i}-A_{3, i} F_{t-1, i}\right)+e_{f, t, i} \\
& \sigma_{s, t, i}^{2}=\alpha_{0, i}+\alpha_{1, i} e_{s, t-1, i}^{2}+\alpha_{2, i} \sigma_{s, t-1, i}^{2}+\alpha_{3, i} D_{s, t-1, i} e_{s, t-1, i}^{2}+\alpha_{4, i} \varepsilon_{f, t-1, i}^{2}+\alpha_{5, i} D_{f, t-1, i}^{0} \varepsilon_{f, t-1, i}^{2} \\
& +\alpha_{6, i} \operatorname{SENT}_{t} e_{s, t-1, i}^{2}+\alpha_{7, i} \operatorname{SENT}_{t} \varepsilon_{f, t-1, i}^{2}+\alpha_{8, i} D_{s, t-1, i} \operatorname{SENT}_{t} e_{s, t-1, i}^{2}+\alpha_{9, i} D_{f, t-1, i}^{0} \operatorname{SENT}_{t} \varepsilon_{f, t-1, i}^{2} \\
& \sigma_{f, t, i}^{2}=\beta_{0, i}+\beta_{1, i} e_{f, t-1, i}^{2}+\beta_{2, i} \sigma_{f, t-1, i}^{2}+\beta_{3, i} D_{f, t-1, i} e_{f, t-1, i}^{2}+\beta_{4, i} \varepsilon_{s, t-1, i}^{2}+\beta_{5, i} D_{s, t-1, i}^{0} \varepsilon_{s, t-1, i}^{2} \\
& +\beta_{6, i} \operatorname{SENT}_{t} e_{f, t-1, i}^{2}+\beta_{7, i} \operatorname{SENT}_{t} \varepsilon_{s, t-1, i}^{2}+\beta_{8, i} D_{f, t-1, i} \operatorname{SENT}_{t} e_{f, t-1, i}^{2}+\beta_{9, i} D_{s, t-1, i}^{0} \operatorname{SENT}_{t} \varepsilon_{s, t-1, i}^{2} \\
& \sigma_{s f, t, i}=\left(\gamma_{0, i}+\gamma_{1, i} S E N T_{t}\right) \sigma_{s, t, i} \sigma_{f, t, i} ; \quad \mathrm{i}=1,6 \text {; } \\
& \text { Model 2: } \alpha_{7, i}=\alpha_{8, i}=\alpha_{9, i}=0 \text {; and } \beta_{7, i}=\beta_{8, i}=\beta_{9, i}=0 \\
& \text { Model 3: } \alpha_{6, i}=\alpha_{7, i}=\alpha_{9, i}=0 \text {; and } \beta_{6, i}=\beta_{7, i}=\beta_{9, i}=0 \\
& \text { Model 4: } \alpha_{6, i}=\alpha_{8, i}=\alpha_{9, i}=0 ; \text { and } \beta_{6, i}=\beta_{8, i}=\beta_{9, i}=0 \\
& \text { Model 5: } \alpha_{6, i}=\alpha_{7, i}=\alpha_{8, i}=0 \text {; and } \beta_{6, i}=\beta_{7, i}=\beta_{8, i}=0
\end{aligned}
$$

where $\left(S_{t-1, i}-A_{3, i} F_{t-1, i}\right)$ is the error correction term imposing the long-term equilibrium on index $i$ in the two markets; $e_{s, t, i}\left(e_{f, t, i}\right)$ is the innovation in the spot (futures) market at day $t$ for index $i$; $\sigma_{s, t, i}^{2}=\operatorname{var}\left(e_{s, t, i} / \Omega_{\mathrm{t}-1, \mathrm{i}}\right)$ is the conditional variance of the spot market and $\sigma_{f, t, i}^{2}=\operatorname{var}\left(e_{f, t, i} / \Omega_{\mathrm{t}-1, \mathrm{i}}\right)$ is the conditional variance of the futures market, where $\Omega_{\mathrm{t}, \mathrm{i}}$ is the information set available at $\mathrm{t}-1$ for index $i$. $\sigma_{s f, t, i}$ is the conditional covariance between spot and futures markets. The innovation $\varepsilon_{s, t, i}\left(\varepsilon_{f, t, i}\right)$ is the information from the spot (futures) market which is transmitted to the futures (spot) market and is not included in $e_{f, t, i}\left(e_{s, t, i}\right)$.The dummy variable SENT has a value of 1 for sentiment scores within the top 25\% and 0 otherwise. We use the Sentix 6 month-ESX 50 Index as the sentiment proxy for the European indices and AAII for the US index. The dummy variable $D_{s, t, i}\left(D_{f, t, i}\right)$ is equal to 1 if $e_{s, t, i}\left(e_{f, t, i}\right)<0$. The dummy variable $D_{s, t, i}^{0}\left(D_{f, t, i}^{0}\right)$ is equal to 1 if $\varepsilon_{s, t, i}\left(\varepsilon_{f, t, i}\right)<0 .{ }^{* * *}, * *$ and *indicate $1 \%, 5 \%$, and $10 \%$ levels of significance, respectively. 
Table 7. Effect of sentiment on hedging using futures contracts. (RVar)

\begin{tabular}{lrrrrrr}
\hline & \multicolumn{1}{l}{ CAC } & \multicolumn{1}{l}{ DAX } & Eurstoxx & \multicolumn{1}{l}{ FTSE } & Ibex35 & \multicolumn{1}{c}{ S\&P500 } \\
\hline TC=0 & & & & & & \\
\hline Naïve & $3.43 \%$ & $1.66 \%$ & $8.07 \%$ & $0.84 \%$ & $14.56 \%$ & $1.43 \%$ \\
h constant & $2.97 \%$ & $0.83 \%$ & $1.50 \%$ & $0.55 \%$ & $11.59 \%$ & $0.48 \%$ \\
$\mathrm{~h}_{\mathrm{t}}$ without sent & $0.03 \%$ & $0.67 \%$ & $0.09 \%$ & $0.05 \%$ & $0.77 \%$ & $0.07 \%$ \\
$\mathrm{RIS}$ & $1.01 \%$ & $80.72 \%$ & $6.00 \%$ & $9.09 \%$ & $6.64 \%$ & $14.38 \%$ \\
\hline TC=0.03\% & & & & & & \\
\hline Naïve & $1.13 \%$ & $0.47 \%$ & $8.59 \%$ & $0.65 \%$ & $9.66 \%$ & $0.72 \%$ \\
$\mathrm{~h}$ constant & $0.65 \%$ & $0.37 \%$ & $2.05 \%$ & $0.37 \%$ & $6.25 \%$ & $0.24 \%$ \\
$\mathrm{~h}$ t without sent & $0.02 \%$ & $0.22 \%$ & $0.46 \%$ & $0.34 \%$ & $1.49 \%$ & $0.03 \%$ \\
RIS & $57.52 \%$ & $78.72 \%$ & $23.86 \%$ & $56.92 \%$ & $64.70 \%$ & $33.33 . \%$ \\
\hline
\end{tabular}

Percentage reduction in the variance $\left(R \operatorname{Var}_{x}\right)$ of the benchmark hedged position using $h_{t}^{\text {Sent }}$ relative to that obtained using the ratio X $\left(h_{t}^{O S e n t}, h\right.$ and 1$) . R \operatorname{Var}{ }_{x}=\frac{\operatorname{Var}\left(R_{H}^{x}\right)-\operatorname{Var}\left(R_{H}^{b}\right)}{\operatorname{Var}\left(R_{H}^{b}\right)}$ where $\operatorname{Var}\left(R_{H}^{x}\right)$ is the variance of the hedged position using the hedge ratio $\mathrm{X}\left(h_{t}^{O S e n t}, h\right.$ and 1)) and $\operatorname{Var}\left(R_{H}^{b}\right)$ is the variance of the hedged position using the dynamic hedge ratio obtained from Model $1\left(h_{t}^{\text {Sent }}\right)$, the model taken as the benchmark for this analysis. The Naïve model assumes a hedge ratio of unity. The constant $h$ model calculates it as unconditional variance over spot and futures returns and the unconditional variance of the futures returns market. The $h_{t}^{\text {OSent }}$ is identical to $h_{t}^{\text {Sent }}$ except that it does not include sentiment in the conditional covariance equation. RIS is the percentage reduction in variance that occurs when sentiment is included in the dynamic hedging strategy (using $h_{t}^{\text {Sent }}$ instead of $h_{t}^{\text {OSent }}$, that is, $R \operatorname{Var}_{h_{t}^{o s}}$ ) with respect to that obtained using the constant ratio (using $h_{t}^{\text {Sent }}$ instead of $h$, that is, $R \operatorname{Var}_{h}$ ) $R I S=\frac{R \operatorname{Var}_{h} \text { osent }}{R V a r_{h}}$. TC is the percentage of transaction cost in relation to the value of the hedging operation. 
Table 8. Effect of sentiment on futures mispricing. Relative absolute $\operatorname{spread}\left(M_{j, t}\right)$

\begin{tabular}{|c|c|c|c|c|c|c|}
\hline & CAC & Dax & Eurostoxx & FTSE & Ibex & US \\
\hline HSent(\%) & 0.113 & 0.171 & 0.2126 & 0.1451 & 0.1285 & 0.142 \\
\hline LSent (\%) & 0.1121 & 0.1756 & 0.2129 & 0.1468 & 0.1295 & 0.142 \\
\hline H-L Misp Ratio & 0.9916 & 1.0269 & 1.0013 & 1.0123 & 1.0072 & 0.9999 \\
\hline $\mathrm{p}$-value1 & 0.8627 & 0.6611 & 0.5727 & 0.7808 & 0.8468 & 0.9991 \\
\hline MSent (\%) & 0.109 & 0.17 & 0.222 & 0.155 & 0.114 & 0.135 \\
\hline H\&LSent (\%) & 0.12 & 0.171 & 0.228 & 0.158 & 0.119 & 0.149 \\
\hline H\&L-M Misp Ratio & 1.1027 & 1.0026 & 1.0268 & 1.0134 & 1.0502 & 1.1007 \\
\hline p-value2 & 0.053 & 0.9541 & 0.5606 & 0.7599 & 0.0967 & 0.0138 \\
\hline
\end{tabular}

HSent(\%) is the average level of mispricing in futures contracts during high sentiment periods, in percentage terms. LSent (\%) is the same for low sentiment periods. High/low sentiment is determined as a function of the level of sentiment in relation to the median of the series. The H-L Misp Ratio is the ratio of mispricing in high sentiment periods to mispricing in low sentiment periods. p-value 1 is the level of significance of the null hypothesis that the H-L Misp Ratio is equal to 1. MSent(\%) is the mean level of mispricing in futures contracts in moderate sentiment periods, in percentage terms. H\&LSent (\%) is the same for extreme (high or low) sentiment periods. In the last two cases, High/Low sentiment is when it is above/below the $75^{\text {th }} / 25^{\text {th }}$ percentiles of the series. Sentiment is considered to be moderate if it is between the $25^{\text {th }}$ and $75^{\text {th }}$ percentiles. The mispricing of futures on index $j$ at time $t M_{j, t}$ is computed as the relative absolute spread between actual futures market prices $F_{j, t}$ and our theoretical cost-of-carry valuation $F_{j, t}^{C C}, M_{j, t}=\frac{\left|F_{j, t}-F_{j, t}^{C C}\right|}{F_{j, t}^{C C}}$. The H\&L-M Misp Ratio is the ratio of mispricing in extreme (high and low) sentiment periods to mispricing in moderate sentiment periods. p-value 2 is the level of significance of the null hypothesis that the H\&L-M Misp Ratio is equal to 1. 